Check for updates

Cite this: RSC Adv., 2017, 7, 47196

\section{In-liquid plasma: a novel tool in the fabrication of nanomaterials and in the treatment of wastewaters}

\begin{abstract}
S. Horikoshi ${ }^{*}{ }^{* a b}$ and N. Serpone ${ }^{c}$
Attempts to generate plasma in liquids have been successful and various devices have been proposed. Many reports have described the optimal conditions needed to generate plasma, and mechanisms have been inferred, together with the composition of the plasma. Elucidation of a stable method (and mechanism) to generate plasma in liquids has led to various active investigations into applications of this new energy source. This review article describes the generator and the generation mechanism of in-liquid plasma, and pays attention to the evolving technology. The characteristics of submerged plasma are summarized and examples of nanomaterials syntheses and wastewater treatment are given, both of which have attracted significant attention. Extreme reaction fields can be produced conveniently using electrical power even without the use of chemical substances and high-temperature high-pressure vessels. Chemical reactions can be carried out and environmental remediation processes achieved with high efficiency and operability with the use of in-liquid plasma. Suggestions for introducing in-liquid plasma to chemical processes are discussed.
\end{abstract}

Received 29th August 2017 Accepted 27th September 2017

DOI: $10.1039 / c 7 r a 09600 c$

rsc.li/rsc-advances

\section{Introduction}

1.1 In-liquid plasma: a novel energy source for chemical reactions

Many chemists think it is strange that as much as or more than 99\% of the substances present in the Universe exist as plasma, whereas the typical gas, solid and liquid states of matter tend to be rather rare in that environment. Compared to the vast scale of the Universe, chemists manufacture products in these states

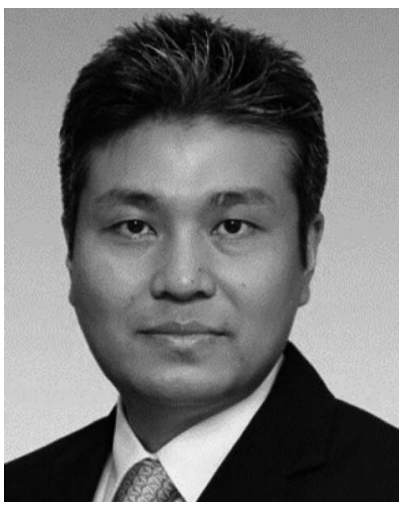

Satoshi Horikoshi (PhD 1999 Meisei University, Tokyo): Associate Professor at Sophia University since 2011 and currently Director of the Japan Society of Electromagnetic Wave Energy Applications (JEMEA); he is on Editorial Advisory Boards of the Journal of Microwave Power and Electromagnetic Energy and three international journals. Research interests involve new functional materials, nanomaterials synthesis, molecular biology, formation of sustainable energy, and environmental protection using microwave- and/or photo-energy, and co-author of over 180 scientific publications and contributor to and editor/co-editor of 23 books. $\mathrm{He}$ is a microwave specialist who often introduces effective methods of using microwave ovens at home on television.

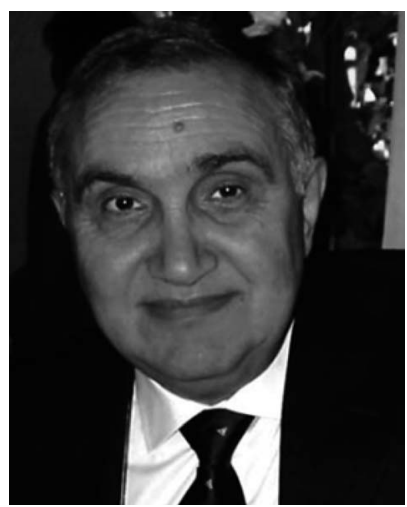

Nick Serpone (PhD, Cornell University, 1968) is a Visiting Professor at the University of Pavia, Italy, a Fellow of the European Academy of Sciences in the Division of Material Sciences, and is currently Head of the Materials Sciences Division of the Academy and Member of the Academy's General Board. His current research interests focus on the photophysics and photochemistry of metal-oxide semiconductors, heterogeneous photocatalysis, photochemistry of sunscreens. He has co-authored over 450 articles and co-edited several monographs. His work has been cited over 34000 times (h-index factor $=93$ ). 
(gas, solid, liquid) with very limited materials. Human beings have used plasmas (e.g., the sun and fire) as energy sources for millennia. These classical energy sources have been used in early chemical syntheses and chemical analyses, even though they are difficult to control in the manufacturing process. Accordingly, electrically powered heaters and steam have been used in carrying out chemical reactions. More recently, microwave chemistry has developed significantly in the use of microwaves as the energy source. ${ }^{1}$ After World War II, the science behind changing substances artificially into plasma and then using this energy source in chemical reactions has been explored actively. However, combinations of plasma and chemical reactions have been limited to solid-phase reactions. Since ordinary plasma mimics a gas, its utilization in the liquid phase has only been possible in irradiating the liquid surface of a sample. Even with strong stirring, the effect of plasma on a liquid sample is not so pronounced. Nonetheless, chemists have considered using plasma as the energy source to activate chemical reactions, even though its use is difficult from the productivity viewpoint.

Recent years have also witnessed the successful generation of stable plasma in solution (referred to as in-liquid plasma); its application in various fields is currently being investigated. Use of in-liquid plasma has attracted significant attention as being a hot research topic. The state of new substances generated in liquids is expected to be a new tool in solution chemistry fostered by a combination of innovative ideas and the promise of novel materials synthesis. For instance, in-liquid plasma could be applied to fuel (hydrogen) recovery from a methane hydrate layer existing in Japanese waters; the method used is detailed in Fig. 1. $^{2}$ It involves irradiating a methane hydrate layer with in-liquid plasma to achieve dehydrogenation reaction

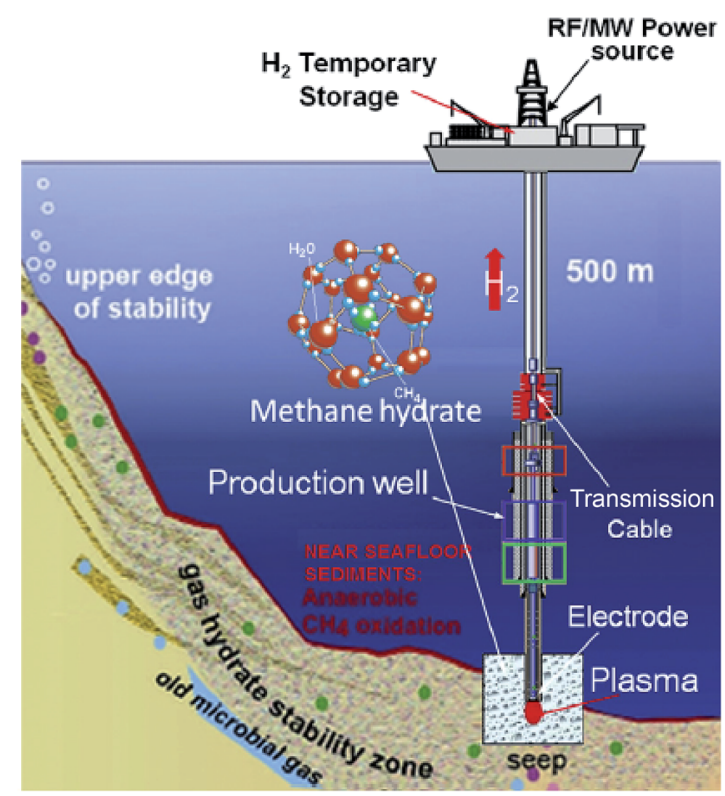

Fig. 1 Process for hydrogen production from hydrate fields in subsea sites using the plasma from the in-liquid method. Reproduced from Rahim and coworkers. ${ }^{2}$ Copyright 2015 by Elsevier. and recover hydrogen energy from bubbles deep in oceanic waters. In the existing method, the methane hydrate is recovered using a pump; however, it is possible to recover the required amount of hydrogen from the seabed without the use of pumps. Depending on conditions, in-liquid plasma can drive various chemical processes.

\subsection{Plasma}

Although plasma is an emerging technology in many fields of application, the history of plasma technology goes as far back as the 18th century. Georg Christoph Lichtenberg (1742-1799), a professor of mathematics in Göttingen (Germany), produced brush discharges by spreading fern spores between two electrodes. $^{3}$

Michael Faraday (1791-1867), discoverer of electromagnetism in 1821, was the first to provide an explanation for Lichtenberg's observations. His countryman, Sir William Crookes (1832-1919), later discovered the fourth state of matter as radiating matter in discharge tubes, ${ }^{4}$ which he correctly assumed to consist of electrically charged gas molecules in the tubes: de facto, plasma was born. He later defined it in his lecture titled "On Radiant Matter" delivered before the British Association for the Advancement of Science, on 22 August 1879 at Sheffield (D. Appleton, The Popular Science Monthly, 1880, Volume 16, pp 157-167). Crookes discovery was followed nearly two decades later (1897) by Sir Joseph John Thomson's (18561940) postulation that atoms consist of positively charged electrons that possess a mass. ${ }^{5}$ This was also confirmed by the German chemist Eugen Goldstein, who discovered that the socalled canal rays consisted of positively charged particles with missing electrons $\left(\mathrm{H}^{+}\right.$ions from hydrogen gas). Thus, plasma had been identified as a mixture of electrons and ions. The term plasma was finally defined by the American chemist Irving Langmuir (1881-1957) who in 1923 observed specific oscillations in an ionized gas that he referred to as plasma oscillations generated from an inhomogeneous charge distribution and to the natural tendency of the charge to redistribute uniformly inside the plasma. ${ }^{6}$ The first comprehensive published report on gas discharges was by the German physicist Johannes Stark (Die Elektrizität in Gasen), then Director of the Institute of Physics of the University of Greifswald. Stark was awarded the 1919 Nobel Prize for the discovery of the Doppler Effect in canal rays and for the splitting of the spectral lines in electric fields (the Stark Effect). At the end of 1918, Stark invited Rudolf Seeliger to the University of Greifswald who remained until 1955. Seeliger is one of the pioneers of modern plasma and gasdischarge physics. The fundamental physical properties of plasma were clarified in the first half of the 20th century by Seeliger and others, which led to rapid advances in the engineering applications of plasmas, ${ }^{7}$ as exemplified by the inventions of the mercury discharge lamp (Cooper Hewitt light: 1902), the mercury arc lamp (1905), and the high-pressure mercury lamp (1906) among others.

Coupling theory and technological innovations in plasma applications also advanced noticeably. In the second half of the 20th century, plasmas were used increasingly for a variety of 
purposes, such as in neon tubes (vacuum) and in etching processes (hot). Technological progress in the mid-1990s also led plasmas to be generated non-thermally under atmospheric pressure, which opened loads of new possibilities since expensive and complex vacuum systems were no longer needed; processes could now be run continuously without putting stress on materials being treated. As a result, plasma-induced processes could then be applied in, for instance, the medical sector for the gentle sterilization of medical equipment and catheters. In 1996, Laroussi ${ }^{8}$ was one of the first to describe a novel sterilization method that used uniform glow discharge plasma generated at atmospheric pressure. He examined the inactivation of Pseudomonas fluorescens bacteria in yeast extract in a polypeptone glucose solution.

Starting with a handful of publications in the mid-1990s, the number of publications that dealt with applications of plasmas increased rapidly at the turn of the 21st century. Indeed, the total number of publications dealing with cold plasma has increased significantly in the past 20 years, attesting to the importance of this emerging technology. As we speak, various engineering application advances are being made. This indispensable technology has developed and currently used extensively in metal welding, in surface treatments, in the processing of materials and electronic components, in the fabrication of nanomaterials, and in wastewater treatment (among others). ${ }^{6}$

Plasma is classified as (i) high-temperature plasma (thermal equilibrium plasma), and (ii) as low-temperature plasma (nonthermal equilibrium plasma). Thermal equilibrium plasma is plasma generated by applying electrical power for a long time under conditions that the gas pressure is $5 \mathrm{kPa}$ or more, and that the electron and gas temperatures are nearly equal. Since the ionization energy of atoms and molecules necessitates several $\mathrm{eV}$ or more (tens of thousands of degrees Celsius), some of the electrons and ions become high-energy particles. In general, the materials temperature in thermal equilibrium plasma reaches as much as several thousand degrees Celsius or more; this plasma is casually used as a heat source and light source for welding and lamps. By comparison, the electron temperature is higher than the gas temperature in non-thermal equilibrium plasma. For example, to convert a gas molecule into non-thermal equilibrium plasma, heat transfer to ions and molecules can be restricted by setting gas molecules to a reduced pressure state and by lowering the frequency of collision of electrons with ions or molecules. A characteristic of non-thermal equilibrium plasma is that its gas temperature is low and electrons are in a high-energy state, and as such it is used in the manufacturing of semiconductors and films through chemical reactions. Since non-thermal equilibrium plasma must maintain reduced pressure conditions, facilities such as a vacuum chamber and a vacuum evacuation device are required, even if plasma were generated by a short pulse discharge under atmospheric pressure conditions. This is often referred to as atmospheric pressure non-thermal equilibrium plasma because it has different properties from the plasma in vacuum.

\section{In-liquid plasma}

\subsection{Why plasma can be generated in a liquid (and in a solid)}

Since plasma is a state of matter generated by a destabilizing gas, one must ask whether plasma can also form in solids and liquids. Some people are still sceptical about this.

2.1.1 Solid plasma. Regardless of such scepticism, an electron in a metal (solid) contains free electrons that can move around a lattice point; collectively, these are oscillating electrons. When an external electric field is applied to a free electron, it acts as if it were an electron in gas plasma. Although the plasma defined by Langmuir is referred to as gas plasma, ${ }^{9}$ when applied to a solid it can be regarded as a solid plasma even for a solid (metals, semiconductors) that possesses free electrons. ${ }^{10}$ The collective oscillation of these free charges (mainly electrons) is known as plasma oscillation; quantizing this oscillation leads to formation of a Plasmon. When metallic nanoparticles are irradiated with specific light, a resonant luminescence appears caused by Plasmon absorption; applications of such nanoparticles in paints, in medical treatment, in measurements, and in microfabrication have been reported. ${ }^{11}$

2.1.2 In-liquid plasma. For years, some techniques have made use of in-liquid plasma to perform electrical discharge machining, welding, and carburizing (and others) in liquids. Yet, only but a few research studies have taken the trouble to explore and exploit in-liquid plasma, so that its use has been rather limited. The report published by Clements in 1987 (ref. 12) on plasma generation by a high-voltage pulse discharge in water (material changed to a plasma state) was a leading research study of the 1980s. Since then, various studies of the physical elucidation of in-liquid plasma have been carried out from many research quarters, which reported that plasma generated in the liquid phase is a phenomenon greatly different from plasma in the gas phase and suggested the use of in-liquid plasma to wastewater treatment as one of several possible applications. Following these reports, researchers worldwide have optimized in-liquid plasmas with regard to such factors as pressure, temperature, density, viscosity, composition, and conductivity $^{13}$ that have led to an accelerated development of inliquid plasma generators. In addition to gas-phase plasma used in academia, the bases of plasma in the solid phase and in the liquid phase are now also academically established; systematization of plasma in each state of matter is progressing (Fig. 2). Research into practical applications is also on the increase.

There are two key methods of generating in-liquid plasma. The first key method is an underwater streamer discharge that produces linear plasma in the liquid; the dielectric breakdown of the liquid turns into a type of corona discharge considering the classification of general plasma. During the dielectric breakdown of water, micro-bubbles are formed near the electrode by cavitation produced either by a high electric field or by heating from a conductive current; the plasma is generated in the micro-bubble. ${ }^{12}$ To generate an underwater streamer discharge, even in an aqueous solution, an electrical power of 50 to $400 \mathrm{kV}$ and a current of $100 \mathrm{~A}$ or more are required. Industrially, it is difficult to achieve and maintain a steady-state 


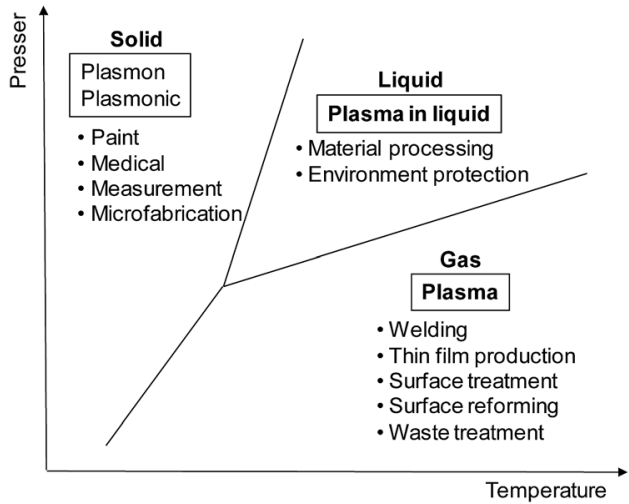

Fig. 2 Relationship between plasma and the three states of matter.

electrical power of this magnitude from the viewpoint of stability and energy saving. Accordingly, many discharges are generated using a pulsed voltage of $1 \mu$ s duration or less. An underwater streamer discharge occurs in liquid at a rate of 30 to

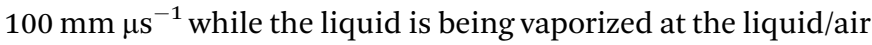
interface. ${ }^{14,15}$ The occurrence of an underwater streamer discharge in the liquid phase generates ultraviolet rays, shock waves, and localized heat, together with chemically active species formed by the resulting plasma. ${ }^{16}$ The second key method is to generate bubbles by heating, by shock waves, and by gas introduction (or the like) in the liquid to create in-liquid plasma. Since applying electrical power is not always accompanied by a dielectric breakdown of the liquid, in many cases plasma can still be generated with a power of $10 \mathrm{~kW}$ or less as a glow discharge, a corona discharge (streamer discharge), and as an arc discharge.

Except for underwater streamer discharge, this review article will restrict its considerations to all in-liquid plasmas as plasma generated in bubbles contained within the liquid.

2.1.3 Chemical composition of plasma generated in a liquid. When plasma is generated in a liquid by ionizing ionexchanged water, a pale white light is observed (Fig. 3a); ${ }^{17}$ the emission spectrum displayed in Fig. $3 \mathrm{~b}$ is attributed to $\mathrm{H}_{\alpha}$ (at $\lambda$ $=656 \mathrm{~nm}$ ) and to $\mathrm{H}_{\beta}$ (at $486 \mathrm{~nm}$ ), and to ${ }^{\circ} \mathrm{OH}$ radicals (at 316 $\mathrm{nm}$ ). Therefore, the source of plasma is not due to dissolved air in water, but rather to vaporized water that has turned into plasma. Peaks derived from dissolved nitrogen and oxygen gases at $\lambda=289 \mathrm{~nm}\left(\mathrm{~N}_{\beta}\right)$ and $\lambda=778 \mathrm{~nm}\left(\mathrm{O}^{*}\right)$ have also been detected as sharp luminescence. ${ }^{18}$

\subsection{Methods to generate in-liquid plasma}

Fig. 4a shows near surface interactions with plasmas generated outside the liquid. ${ }^{19}$ From the cocktail of plasma, such species as radicals, ions, electrons and photons are thought to interact, to differing degrees, with the liquid interface, thereby initiating reactions that cascade well into the liquid phase, possibly via biochemical pathways (Fig. 4a). Radicals, ions and photons are often considered, but in attempts to isolate important sources of reactions within liquids, it is also necessary to consider electron interactions directly with the liquid phase (Fig. $4 \mathrm{~b}$ and
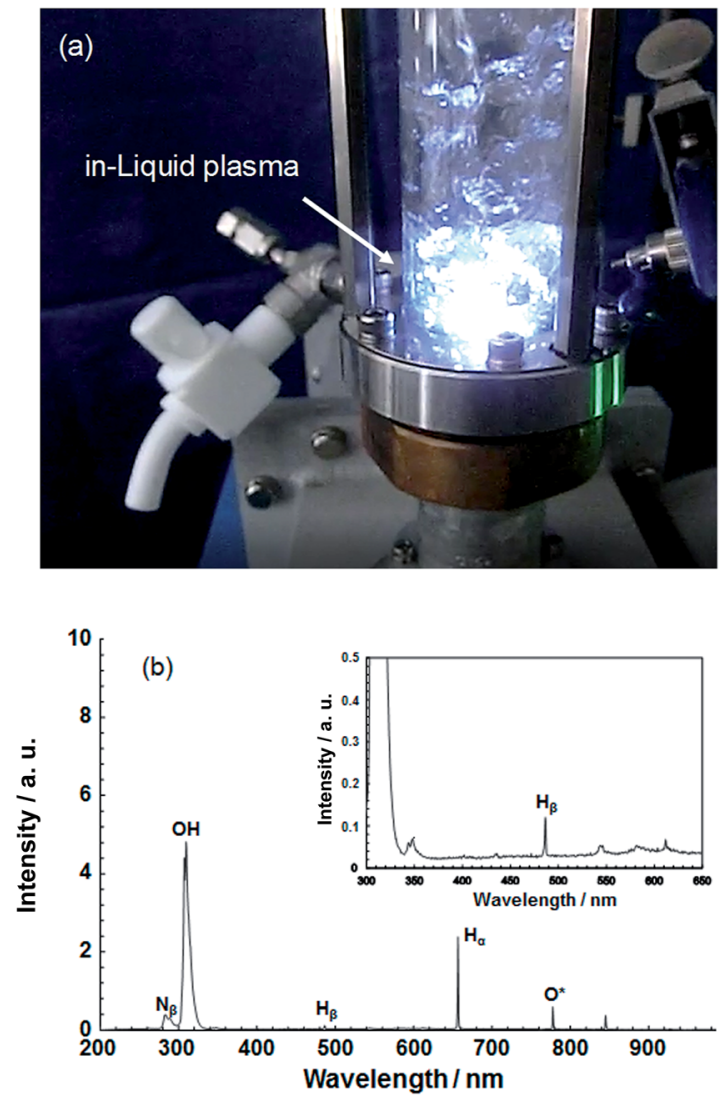

Fig. 3 (a) Photograph illustrating the generation of plasma in liquid using a microwave power supply; (b) spectrum of ultraviolet and visible light emitted by in-liquid plasma generated in ion-exchanged water. Taken from ref. 17. Copyright 2017 by S. Horikoshi.

c); to date, these have received little attention. Accordingly, the focus of this paper will be restricted to phenomena occurring under plasma conditions as illustrated in Fig. $4 \mathrm{~b}$ and c.

Currently, methods to generate in-liquid plasma can be broadly divided into four categories, and since each possesses

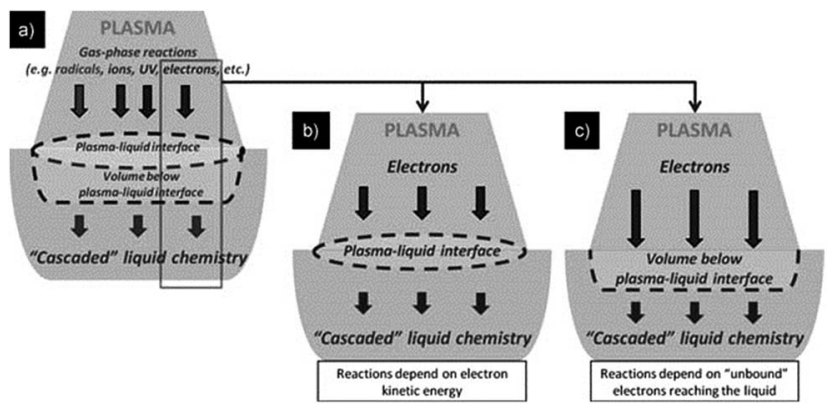

Fig. 4 Schematic diagram of three different types of plasma in-liquid conditions (PiLC): (a) gas-phase species and plasma-radiationinduced liquid reactions at the plasma-liquid interface; ( $b$ and $c$ ) electrons from the plasma can initiate non-equilibrium reactions in the liquid phase where both electron energy distribution (b) and electron density play an important and distinct role (c). Reproduced from Mariotti et al. ${ }^{19}$ Copyright 2012 by WILEY-VCH. 
its own characteristics, it is necessary to select the appropriate plasma according to purpose and end-use. Considering electrode configurations and energy sources, generated in-liquid plasma can be subdivided as:

(1) Plasma A: direct discharge between two electrodes using an AC (plus) power supply.

(2) Plasma B: contact discharge between an electrode and the surface of the surrounding electrolyte using a DC power supply.

(3) Plasma C: plasma generated with either radio frequency (RF) or microwave (MW) irradiation.

(4) Plasma D: plasma generated using the laser ablation technique.

The schematic of generating Plasma A involves a direct discharge between two electrodes that comes in such forms as solution plasma, discharge plasma in liquid, electric spark discharge, arc discharge, capillary discharge, and streamer discharge (Fig. 5a). Two electrodes of similar size and shape are immersed in the liquid at a short distance. Because of the direct discharge, most liquids containing conductive electrolytes in such media as deionized water, ethanol, and liquid nitrogen can be used. Thus, in-liquid plasma is generated between the two electrodes immersed in the electrolyte solution after passing an electric current through the solution. It is important that the liquid used in this method be conductive.

The schematic of Plasma B is displayed in Fig. 5b. In 1963, Hickling and Ingram reported contact glow discharge electrolysis (CGDE), ${ }^{20}$ whereby a high-temperature plasma sheath formed between an electrode and the surface of the surrounding electrolyte as a result of a high electric field; this was subsequently accompanied by a glow discharge photoemission. Consider now two electrodes immersed in a conductive electrolyte in which the distance between them is varied from $5 \mathrm{~mm}$ to over $100 \mathrm{~mm}$, and the electrode surface area between the anode and cathode is different; one of the electrodes has a smaller surface area than the other. The electrode
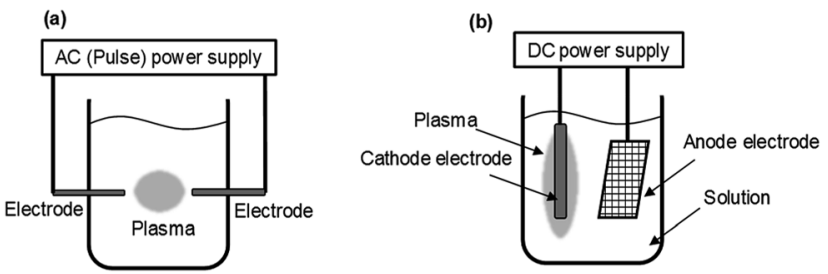

(c)

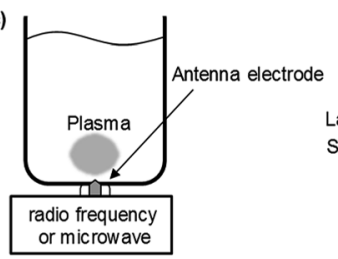

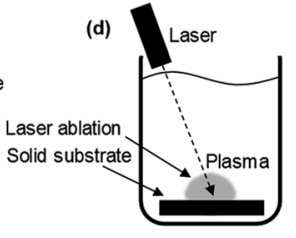

Fig. 5 Images of plasma generation method in a liquid: (a) direct discharge between two electrodes using an AC (plus) power supply; (b) contact discharge between an electrode and the surface of the surrounding electrolyte using a DC power supply; (c) plasma generation with radio frequency (RF) or microwave (MW) irradiation; (d) plasma generation using the laser ablation method. with the smaller surface area is covered with a thin film of water vapor within which a discharge occurs. In a submerged plasma two-electrode generator that uses a direct current power supply, passing the electric current through the electrolyte liquid produces foam owing to Joule heating; the in-liquid plasma is generated at the cathode side. In such a system, as the conductivity of the liquid changes, the conditions under which the in-liquid plasma is generated also change, so that it is necessary to keep the conductivity at an appropriate level. In most cases, the cathode consists of a metal plate with a large surface area (e.g., a Pt mesh), while the anode is a metal wire. A stable DC power supply is often used, although pulsed DC has also been used.

Techniques for generating in-liquid plasma by irradiating an antenna electrode with radio frequency or microwaves for Plasma $\mathrm{C}$ have been utilized in a variety of fields (Fig. 5c). These techniques are effective in generating in-liquid plasma at a lower electrical power. In the plasma generating apparatus, the dielectric constant and the dielectric loss of the liquid are important factors in the generation process. Unlike other techniques, however, it is not necessary to use an electrolyte solution. Radio frequency or microwave generated in-liquid plasma can be maintained in water over a wide range of water conductivity (from 0.2 to $7000 \mathrm{mS} \mathrm{m} \mathrm{m}^{-1}$ ). When plasma is generated in a solution using radio frequency or microwaves, a lower pressure is often applied because energy is absorbed by water as it possesses a dielectric constant and dielectric loss. An advantage here is that plasma can be generated even in pure water, and so various application developments can be expected.

Another method for generating plasma in a liquid uses the laser ablation technique (Plasma D; Fig. 5d). The laser irradiates a solid substrate immersed in the liquid causing a plasma ball to be generated on the surface of the solid. This technology is applied in such research as nanoparticle production ${ }^{\mathbf{2 1}}$ and deepsea mass spectrometry. ${ }^{22}$

The various techniques for generating Plasma A-C proposed according to usage conditions, reaction conditions, and operating equipment (among others) have been classified in some detail by Saito and Akiyama ${ }^{23}$ who explained the classification based on the corresponding engineering diagram for the Plasma A-C summarized in Fig. $6,^{23-84} 7,{ }^{85-128}$ and $8 .^{129-154}$

\subsection{Problems and countermeasures in plasma generation}

To generate plasma continuously in a liquid necessitates application of a large electrical power as compared to the case of generating plasma in vacuum or under atmospheric pressure, so that the thermal load on the electrode is large. Consequently, studies on electrodes used in plasma generation have been carried out for many years. In-liquid plasmas have been generated using electrodes made with such materials as tungsten, aluminum, copper, molybdenum, stainless steel (SUS 304), and carbon. Plasma generation with electrodes made of carbon, molybdenum, and SUS 304 lasted no more than 5 min. ${ }^{155}$ Moreover, continuous (for $10 \mathrm{~min}$ ) in-liquid plasma generation with aluminum and copper electrodes caused 


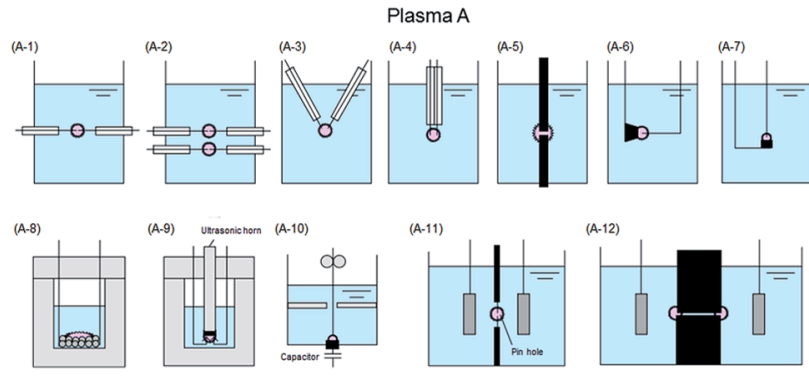

Fig. 6 Typical electrode configuration for Plasma A: (A-1) influence of glow discharge plasma and dielectric barrier discharge; ${ }^{24-30}(A-2)$ dielectric barrier discharge in quartz tube; ${ }^{31}(\mathrm{~A}-3)$ gliding arc discharge; ${ }^{32}$ (A-4) gas-liquid interfacial plasma, plasma electrochemistry in ionic liquids, and so forth, ${ }^{33-45}(\mathrm{~A}-5)$ glow discharge formation over water surface; ${ }^{46}$ (A-6) discharge electrolysis; ${ }^{47-64}$ (A-7) microplasma; ${ }^{19,65-75}$ (A-8) dual plasma electrolysis; ${ }^{76}(A-9)$ plasma in contact with liquids; ${ }^{77,78}$ (A-10) microplasma discharge; ${ }^{79}$ (A-11) glow discharge generated in contact with a flowing liquid cathode; ${ }^{80-84}$ (A-12) AC capillary discharge. Modified with permission from ref. 23. Copyright 2015 by Hindawi.

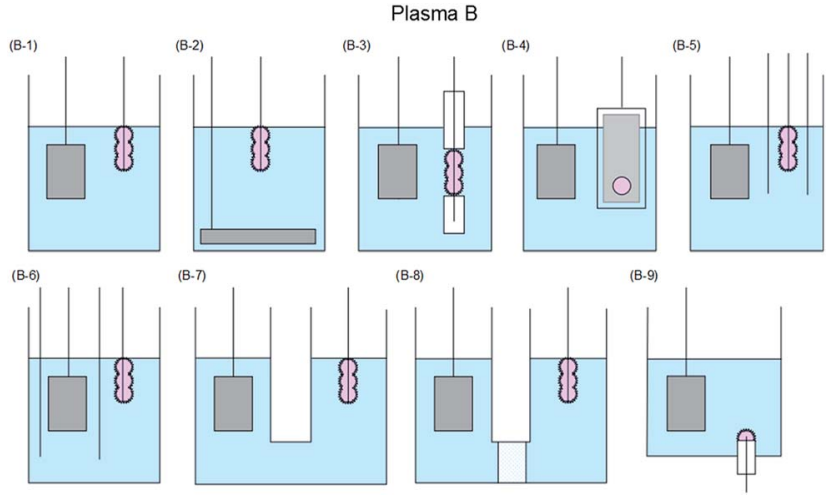

Fig. 7 Typical electrode configuration for Plasma B: (B-1) contact glow discharge; ${ }^{.85-108}$ (B-2) electrical discharges, ${ }^{109-111}$ streamer discharge plasma in water:112 (B-3) solution plasma, ${ }^{91,93,99,113}$ electric discharge plasma; ${ }^{114}$ (B-4) contact glow discharge:;13,115,116 (B-5) contact glow discharge; ${ }^{117}$ (B-6) contact glow discharge electrolysis:118-120 (B-7) high-voltage cathodic polarization; ${ }^{121}(B-8)$ contact glow discharge electrolysis, ${ }^{118,122-125}$ and (B-9) electrical discharge. ${ }^{126-128}$ Modified with permission from ref. 23. Copyright 2015 by Hindawi.

deterioration of the electrode surface. On the other hand, for electrode material with high melting points (e.g., tungsten, $\mathrm{mp}$ $=3422{ }^{\circ} \mathrm{C}$ ), the electrode could, in principle, withstand longterm use (Fig. 9). Nonetheless, deterioration of the electrode surface can still occur depending on the generation conditions of the in-liquid plasma. Therefore, studies on the mechanism of in-liquid plasma heating of the electrodes and improvement measures are ongoing.

Many of the currently reported in-liquid plasmas produce bubbles within which plasma is generated in the liquid. However, if the bubble generating device were to be connected separately, the physical structure of the plasma generating portion would get rather complicated. To resolve this problem, an ultrasonic wave irradiation device is installed in the vicinity

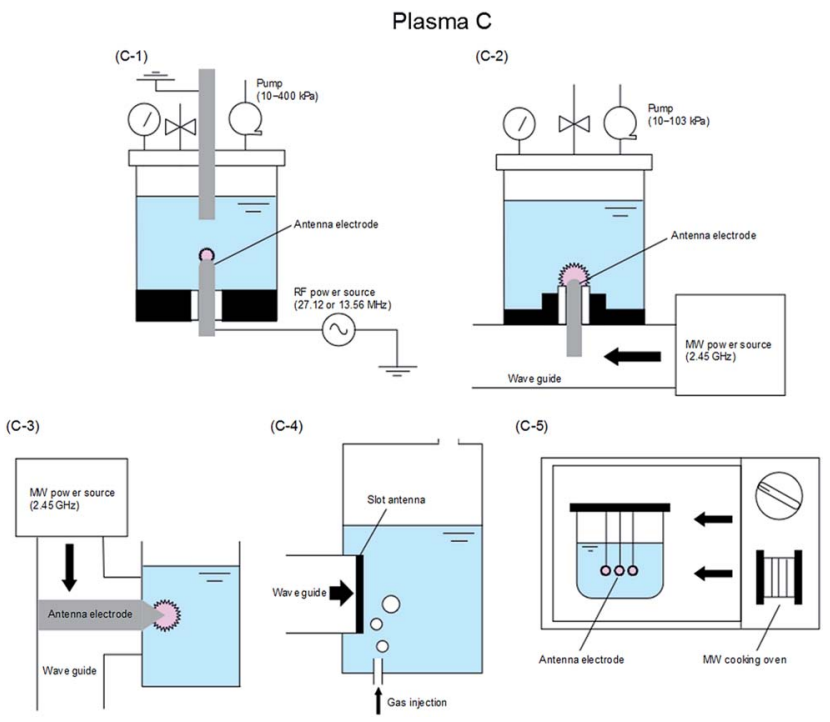

Fig. 8 Typical electrode configuration for Plasma C: (C-1) RF applied in-liquid plasma system under vacuum condition; ${ }^{129-140}$ (C-2) MW applied in-liquid plasma system under vacuum condition;, ${ }^{134,141-149}$ (C3) MW-induced in-liquid plasma system under atmosphere condition; ${ }^{150,151}$ (C-4) slot-excited MW discharge in-liquid plasma system under atmosphere condition; ${ }^{152}$ and (C-5) in-liquid plasma generation system with a MW oven. ${ }^{153,154}$ Modified with permission from ref. 23. Copyright 2015 by Hindawi.

of the plasma generating electrode. Even with this method, however, it is not possible to improve the apparatus complexity in the vicinity where plasma is generated. Accordingly, an apparatus has been developed in which the electrode and the ultrasonic homogenizer horn are integrated.

For instance, by sharing the microwave antenna electrode with the ultrasonic homogenizer as an in-liquid plasma apparatus driven by a single microwave power supply, both microwaves and ultrasonic waves can be used to irradiate simultaneously, thereby simplifying the apparatus (Fig. 10). ${ }^{\mathbf{1 5 6}}$ Since the ultrasonic homogenizer can generate fine bubbles in the liquid, they can be produced in the very vicinity where
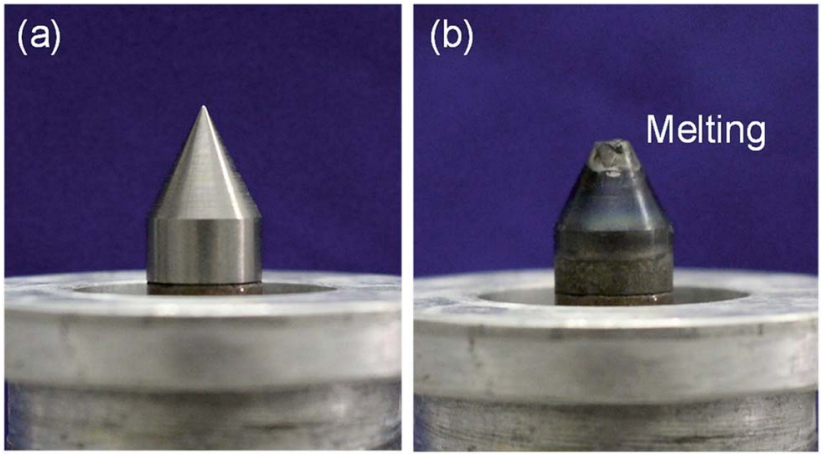

Fig. 9 (a) Photograph of a tungsten pencil-type electrode of an inliquid plasma generator of the microwave type in an unused state; (b) photograph of a tungsten pencil-type electrode after several minutes of generating in-liquid plasma with continuous microwaves. Taken from ref. 17. Copyright 2017 by S. Horikoshi. 


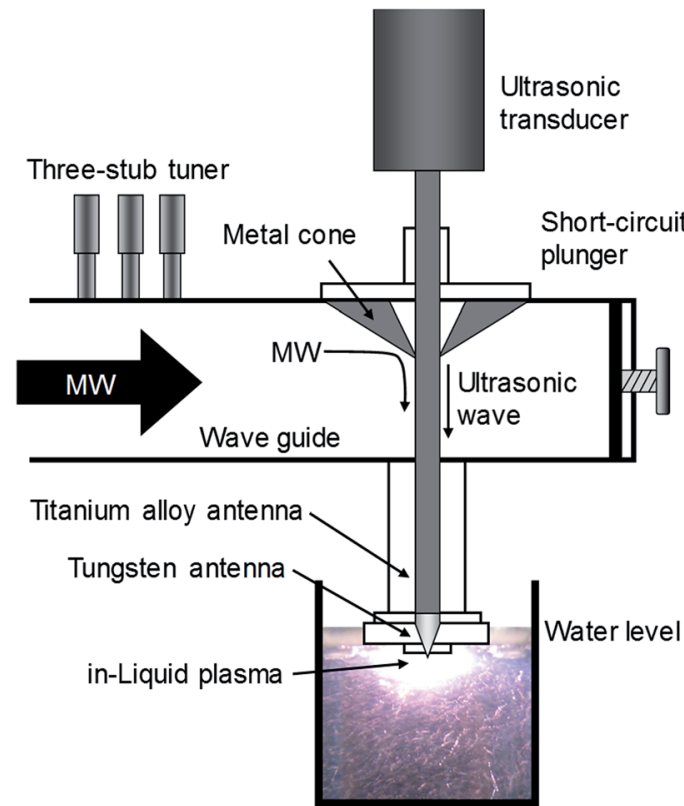

Fig. 10 Schematic diagram of an ultrasonic/microwave simultaneous irradiation type in-liquid plasma generator system. Reproduced from Horikoshi et al. ${ }^{156}$ Copyright 2017 by Elsevier.

plasma is generated, causing plasma to be generated efficiently in the bubbles. Using the latter method, even if the incident power of the microwaves were reduced by $45 \%$ or more, compared to the existing apparatus without ultrasonic waves, in-liquid plasma could still be generated continuously and deterioration of the electrode could be minimized if not suppressed for long periods of use.

\section{In-liquid plasma applications}

\subsection{Nanomaterials synthesis}

3.1.1 Noble metals, alloys and metal-oxide nanoparticles. Two methods have been reported for nanoparticle synthesis using in-liquid plasma. The first method utilizes dissolution of the electrode described in Section 2.3. In the case of in-liquid plasma, dissolution of the electrode surface proceeds by local heating; utilizing this phenomenon provides a method in which nanoparticles are produced by aggregating the electrode metal while evaporating the electrode surface (evaporation method). The second method (reduction method) involves reduction of a metal salt in aqueous media with the in-liquid plasma to synthesize metal nanoparticles. Nanoparticle synthesis by a gasphase plasma reduction method has already been achieved; however, substituting this by a liquid-phase plasma increases the number of molecules of raw materials contained in the system by orders of magnitude. Hence, at laboratory level, for example, a yield of more than $10 \mathrm{~g} \mathrm{~h}^{-1}$ can be obtained. In addition, unlike the nanoparticle synthesis process occurring by gas-phase plasma, aggregation of generated particles can be prevented immediately by adding a particle agglutination inhibitor (or the like) into the solution.

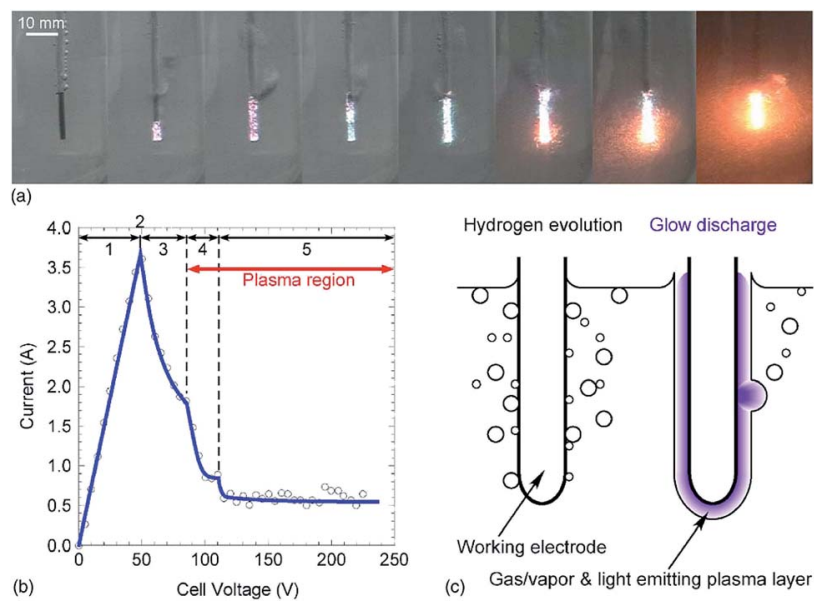

Fig. 11 (a) Photograph of plasma emission during the formation of nanoparticles; (b) relationship between current and voltage; (c) cartoon illustrating the process of nanoparticle generation. Reproduced from Toriyabe et al. ${ }^{88}$ Copyright 2007 by the American Institute of Physics.

Dissolution of the electrode method. Studies have been conducted on the evaporation method to form various metallic nanoparticles by placing cathode electrodes of various metals in a potassium carbonate solution, followed by applying a direct current to this solution to evaporate and dissolve the electrodes. Metallic nanoparticles have been formed in solution during the evaporation of $\mathrm{Ni}, \mathrm{Ti}, \mathrm{Ag}$, and $\mathrm{Au}$ nanowire electrodes with inliquid plasma (Fig. 11) ${ }^{88}$ The advantage of this method is that various kinds of nanoparticles can easily be formed in a liquid by simply changing the kind of metal used for the wire electrode. Along similar lines, Saito and coworkers ${ }^{94}$ reported the syntheses of a single crystal tin oxide plate (SnO) and a $\mathrm{Sn}_{6} \mathrm{O}_{4}(\mathrm{OH})_{4}$ skeleton using tin wire immersed in an electrolyte solution.

The size and shape of these nanoparticles can be controlled by changing the synthesis conditions (reaction temperature, cooling temperature, dispersant) of generating in-liquid plasma (Fig. 12) ${ }^{94}$ And even if plasma conditions were changed, the morphology and the nature of nanoparticles could still be controlled (Fig. 13). ${ }^{99}$ Metal electrodes can be volatilized using wide-area plasma, partial plasma, and partial plasma under high-temperature conditions. Accordingly, it is possible to produce $\mathrm{Ti}, \mathrm{Fe}, \mathrm{Ni}, \mathrm{Cu}, \mathrm{Zn}, \mathrm{Zr}, \mathrm{Nb}, \mathrm{Mo}, \mathrm{Ag}, \mathrm{W}, \mathrm{Pt}, \mathrm{Au}$, and SUS 316 nanoparticles using in-liquid plasma as the energy source. In addition, alloy nanoparticles of gold and platinum can be made by the simultaneous evaporation of the two electrode materials with in-liquid plasma (Fig. 14). ${ }^{157}$ Another study reported the evaporation of a platinum electrode with in-liquid plasma to produce platinum nanoparticles (particle size, 2 $\mathrm{nm}$ ) supported on a highly conductive carbon black support dispersed in water. ${ }^{158}$ This Pt/C catalyst was produced with very high efficiency and used as a catalyst in fuel cells.

Reduced reaction with plasma method. Zinc oxide nanoparticles (ZnO NPs) have been produced using in-liquid plasma. ${ }^{90}$ In this case, a $\mathrm{Zn}$ wire (the cathode) and a mesh 


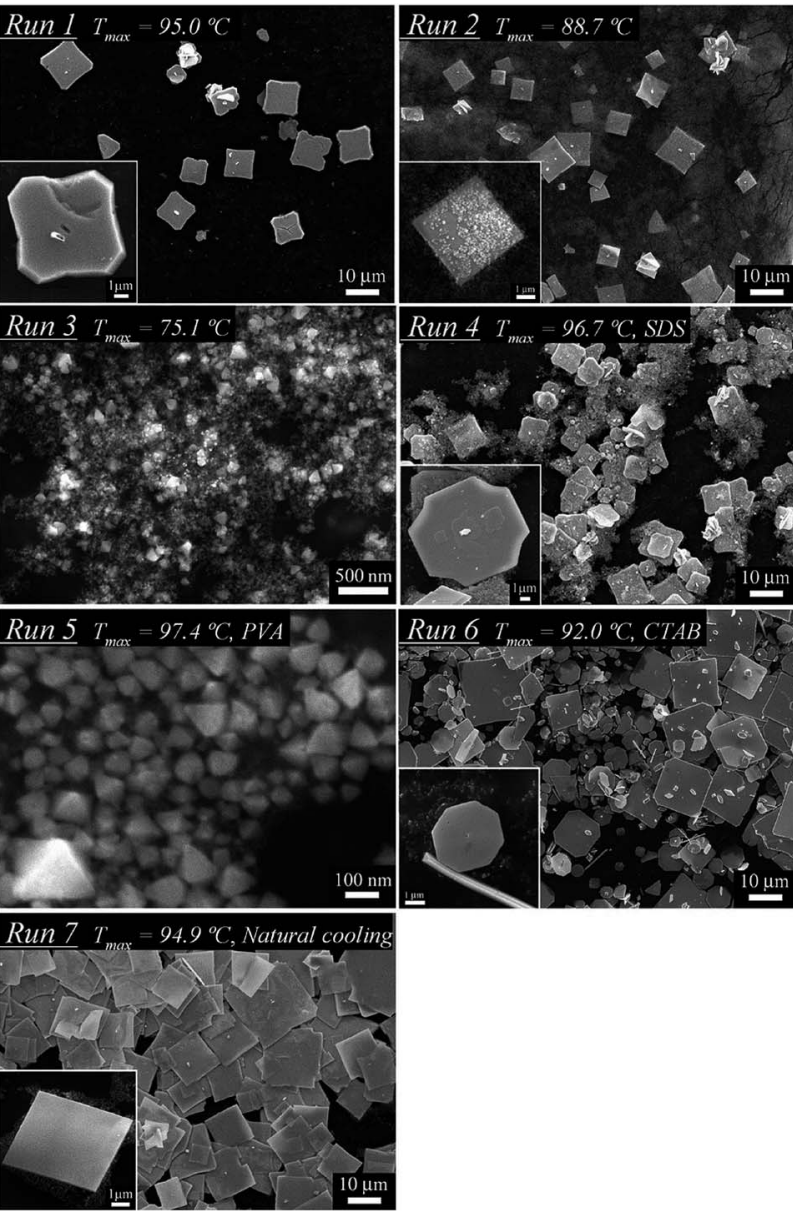

Fig. 12 SEM images of single crystals of a tin oxide $\mathrm{SnO}$ plate synthesized by in-liquid plasma under different reaction temperatures, dispersant and cooling conditions. Reproduced from Saito et al. ${ }^{94}$ Copyright 2012 by the American Chemical Society.
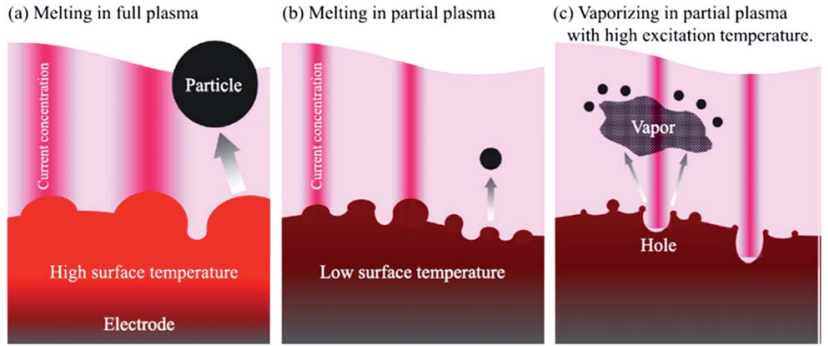

Fig. 13 Images of (a) a wide-area plasma; (b) a partial plasma; and (c) the volatilization of a metal electrode by partial plasma under high temperature conditions. Reproduced from Saito et al. ${ }^{99}$ Copyright 2014 by the American Institute of Physics.

made of Pt wire (the anode) were submersed in an aqueous solution of $\mathrm{K}_{2} \mathrm{CO}_{3}$. Application of a certain voltage to the solution system generated plasma in the immersed part of the $\mathrm{Zn}$ wire. Using medium-power input levels resulted in the formation of flower-like ZnO NPs (Fig. 15a and b), ${ }^{90}$ while applying high-power input levels yielded aggregated ZnO NPs (Fig. 15c);

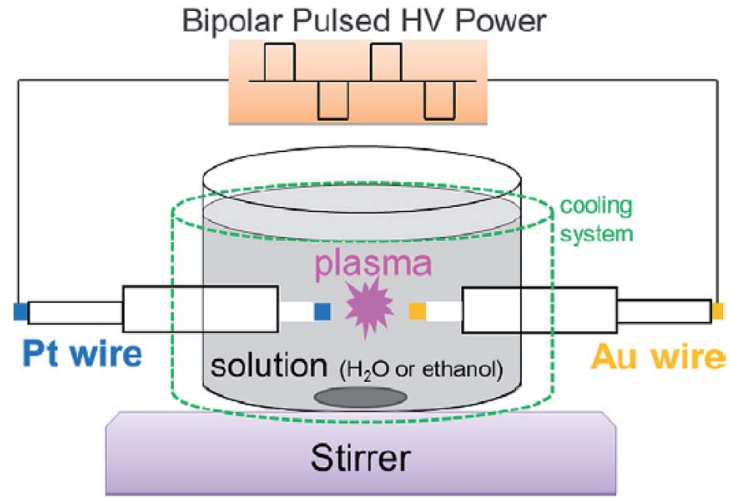

Fig. 14 Image of a synthesis apparatus of a gold/platinum alloy by inliquid plasma using gold and platinum electrodes. Reproduced from Hua and coworkers. ${ }^{157}$ Copyright 2013 by Elsevier.

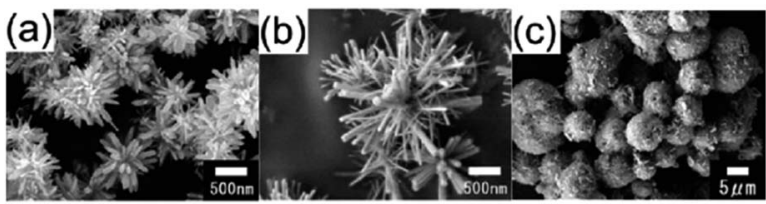

(d)
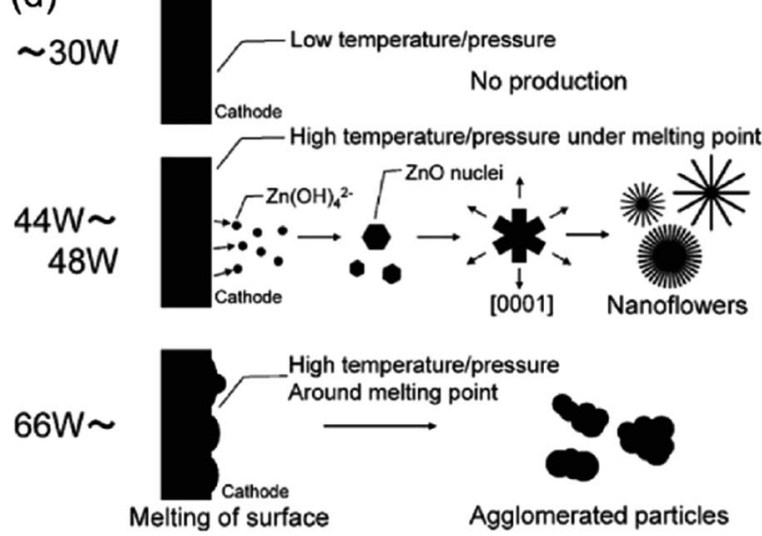

Fig. 15 SEM images of products obtained from in-liquid plasma usage; experimental conditions of $\mathrm{K}_{2} \mathrm{CO}_{3}$ concentration, and discharge voltage/power are: (a) $1.0 \mathrm{M}, 66 \mathrm{~V} / 44 \mathrm{~W}$, (b) $0.5 \mathrm{M}, 80 \mathrm{~V} / 48 \mathrm{~W}$, (c) $0.01 \mathrm{M}, 200 \mathrm{~V} / 168 \mathrm{~W}$. (d) Schematic processes in the synthesis of $\mathrm{ZnO}$ nanoflowers and $\mathrm{ZnO}$ aggregates using in-liquid plasma. Modified with permission from ref. 90. Copyright 2011 by Elsevier.

the mechanism of the synthesis is summarized in Fig. 15d. The $\mathrm{Zn}$ wire is first oxidized to $\mathrm{ZnO}$ on its surface after plasma generation. At low power, the surface temperature of the electrode is below the melting point of zinc and some $\mathrm{Zn}(\mathrm{OH})_{4}{ }^{2-}$ species form around the $\mathrm{Zn}$ wire (reaction (1)).

$$
\mathrm{ZnO}(\mathrm{s})+\mathrm{H}_{2} \mathrm{O}+2 \mathrm{OH}^{-} \rightarrow \mathrm{Zn}(\mathrm{OH})_{4}{ }^{2-}
$$

Subsequently, $\mathrm{Zn}(\mathrm{OH})_{4}{ }^{2-}$ migrates to the low-temperature zone and decomposes into $\mathrm{ZnO}$ (reaction (2)).

$$
\mathrm{Zn}(\mathrm{OH})_{4}{ }^{2-} \rightarrow \mathrm{ZnO}(\mathrm{s})+\mathrm{H}_{2} \mathrm{O}+2 \mathrm{OH}^{-}
$$


The ZnO nanoparticles grow preferentially along the [0001] direction ${ }^{\mathbf{1 5 9 , 1 6 0}}$ to form the flower-like $\mathrm{ZnO}$ nanoparticles. However, at high power (i.e., at $>300 \mathrm{~W} \mathrm{~cm}^{-2}$ (ref. 90)), the temperature of the $\mathrm{Zn}$ wire reaches its melting point causing rapid evaporation of the $\mathrm{Zn}$ wire and the $\mathrm{ZnO}$ film resulting in ZnO particle aggregates (Fig. 15c).
Research studies are also being conducted actively on a reduction method to synthesize various nanoparticles. For instance, gold-based bimetallic particles, (e.g., $\mathrm{Au}-\mathrm{Fe}, \mathrm{Au}-\mathrm{Ga}$, $\mathrm{Au}$-In or the like) can be produced using a metal-ion reduction method and a metal nitrate as the precursor from bivalent $\mathrm{sp}$ metals, trivalent sp metals, or $3 \mathrm{~d}$ and $4 \mathrm{~d}$ metals. A one-step

Table 1 Synthesis of noble metals, alloys and metal-oxide nanoparticles using various in-liquid plasma-related methods (see Fig. 6 for the inliquid plasma methods)

\begin{tabular}{|c|c|c|c|}
\hline Nanoparticles produced & Starting materials & In-liquid plasma methods & Ref. \\
\hline \multirow[t]{4}{*}{$\mathrm{Au}$} & \multirow[t]{2}{*}{ Gold rod or wire } & Plasma A & $165-169$ \\
\hline & & Plasma B & 88, 99 and 114 \\
\hline & $\mathrm{HAuCl}_{4}$ & Plasma A & $170-179$ \\
\hline & $\mathrm{NaAuCl}_{4}$ & Plasma B & 86 \\
\hline \multirow[t]{3}{*}{$\mathrm{Ag}$} & Silver rod or wire & Plasma A & $180-183$ \\
\hline & $\mathrm{AgNO}_{3}$ & Plasma A & 184 and 185 \\
\hline & Ag-zeolite & Plasma A & 186 \\
\hline \multirow[t]{4}{*}{$\mathrm{Pt}$} & \multirow[t]{3}{*}{ Platinum wire } & Plasma A & 187 \\
\hline & & Plasma B & 96 \\
\hline & & Plasma C & 151 \\
\hline & $\begin{array}{l}\mathrm{H}_{2} \mathrm{PtCl}_{6} \\
\text { Nickel wire }\end{array}$ & Plasma B & 86 \\
\hline & $\mathrm{CuSO}_{4}$ & Plasma B & 86 \\
\hline \multirow[t]{2}{*}{$\mathrm{Ni}$} & \multirow[t]{2}{*}{ Nickel wire } & Plasma A & 96 \\
\hline & & Plasma B & $88,89,96$ and 106 \\
\hline \multirow{3}{*}{$\mathrm{Cu}$} & Copper wire & Plasma A & 188 \\
\hline & $\mathrm{CuCl}_{2}$ & Plasma A & 189 and 190 \\
\hline & $\mathrm{CuSO}_{4}$ & Plasma B & 86 \\
\hline $\mathrm{Zn}$ & Zinc plate & Plasma C & 144 \\
\hline Sn & Tin rod & Plasma B & 98 and 101 \\
\hline $\mathrm{Pt}-\mathrm{Au}$ & $\mathrm{Pt}$ and $\mathrm{Au}$ wires & Plasma A & 157 \\
\hline $\mathrm{Pt}-\mathrm{Au}$ & $\mathrm{H}_{2} \mathrm{PtCl}_{6}, \mathrm{NaAuCl}_{4}$ & Plasma B & 86 \\
\hline $\mathrm{Ag}-\mathrm{Pt}$ & $\mathrm{Ag}$ and Pt rod & Plasma A & 191 \\
\hline $\mathrm{Ni}-\mathrm{Cr}$ & Alloy wire & Plasma B & 102 \\
\hline \multirow[t]{2}{*}{$\mathrm{TiO}_{2}$} & \multirow[t]{2}{*}{ Titanium rod } & Plasma A & 88, 95 and 197 \\
\hline & & Plasma B & 109 \\
\hline Defective black $\mathrm{TiO}_{2}$ & Ti wire & Plasma B & 198 \\
\hline Pt nanoparticles supported on $\mathrm{TiO}_{2}$ nanotube & $\mathrm{TiO}_{2}$ nanotube and Pt wires & Plasma B & 199 \\
\hline Cellulose-ZnO composite & $\begin{array}{l}\mathrm{Zn}\left(\mathrm{O}_{2} \mathrm{CCH}_{3}\right)_{2} \cdot 2 \mathrm{H}_{2} \mathrm{O} \\
\text { (or anhydrous } \mathrm{Zn} \text { acetate) and D-glucose }\end{array}$ & Plasma A & 200 \\
\hline $\mathrm{CuO}$ & Copper foil & Plasma B & 201 \\
\hline $\mathrm{Cu}_{2} \mathrm{O}$ & Copper plate & Plasma B & 202 \\
\hline $\operatorname{In}(\mathrm{OH})_{3}$ nanocubes & Indium and tin plate & Plasma B & 203 \\
\hline Fullerene $\left(\mathrm{C}_{60}\right)$ & Graphite in toluene & Plasma A & 204 \\
\hline Carbon nanotubes (CNT) & Carbon rods & Plasma A & $205-209$ \\
\hline CNT-supported Pt nanoparticles & $\mathrm{Pt}, \mathrm{H}_{2} \mathrm{PtCl}_{6}, \mathrm{CNT}$ & Plasma A & 210 \\
\hline Carbon-metal nanocomposites & $\begin{array}{l}\text { Platinum, aluminium, nickel, } \\
\text { copper, tungsten, carbon electrodes }\end{array}$ & Plasma B & 211 \\
\hline $\mathrm{Ag}$ on mesoporous silica & Ag NPs, tetraethylorthosilicate (TEOS) & Plasma A & 212 and 213 \\
\hline
\end{tabular}


synthesis of nanoparticles in water has also been described. ${ }^{\mathbf{1 6 1}}$ Stable gold bimetallic nanoparticles of 5 to $20 \mathrm{~nm}$ can be synthesized using this method. On the other hand, in the case of microwave-generated in-liquid plasma $(2.45 \mathrm{GHz})$, Toyota and coworkers ${ }^{\mathbf{1 6 2}}$ succeeded in depositing diamond particles (7 to $8 \mu \mathrm{m}$ ) onto silicon wafers to produce a diamond electrode in methanolic media. Syntheses of $\mathrm{Cu}, \mathrm{Au}$, and Pt nanoparticles by the in-liquid plasma reduction method have also been described. ${ }^{\mathbf{1 5 1}}$

In fact, syntheses of nanomaterials have been reported extensively as there are many advantages in using the energy from in-liquid plasma to drive a chemical reaction. Thus, various nanoparticles of noble metals, alloys and metal-oxide nano-materials have been synthesized using various types of plasma-related techniques. Some of the nanoparticles, starting materials and type of in-liquid plasma used are summarized in Table 1.

Panomsuwan and co-workers ${ }^{\mathbf{1 6 3}}$ reported that metal-free $\mathrm{N}$ doped carbon nanoparticles (NCNPs) could be synthesized via a solution plasma process with the potential to achieve uniformly distributed nitrogen atoms. Accordingly, they used a set of cyanoaromatic molecules that included benzonitrile, 2cyanopyridine and cyanopyrazine as a single-source precursor in the synthesis without the addition of a metal catalyst. The resulting NCNPs revealed uniformly nanosized particles (20-40 $\mathrm{nm}$ ) and an interconnected hierarchical pore structure with a high specific surface area (210-250 $\left.\mathrm{m}^{2} \mathrm{~g}^{-1}\right)$. The difference in carbon/nitrogen mol ratios of organic precursors gave rise to the variation of nitrogen-doping level in NCNPs from 0.63 to 1.94 atom\%. A detailed electrochemical evaluation toward the oxygen reduction reaction (ORR) demonstrated that NCNPs exhibit a significant improvement in terms of both onset potential and current density under alkaline and acidic conditions. The predominant distribution of graphitic- $\mathrm{N}$ and pyridinic-N sites on NCNPs played an essential role in enhancing the ORR activity and the selectivity toward a fourelectron reduction pathway. More importantly, NCNPs possessed excellent robust long-term durability and strong methanol tolerance compared with those of a commercial Pt/ carbon catalyst. The possible formation mechanism of NCNPs is illustrated schematically in Fig. 16. After discharging for $30 \mathrm{~min}$, black solid particles were separated from the liquid precursor by pouring through a filter paper and washed several times with ethanol until the wash solvent was colorless. The solution plasma approach used ${ }^{\mathbf{1 6 3}}$ should broaden and accelerate further research efforts on nitrogen-doped carbon catalysts, one-step closer to practical fuel cells and other related electrochemical devices.

Morishita and co-workers ${ }^{164}$ investigated the routes of solution-plasma-induced nanocarbon formation from hexane, hexadecane, cyclohexane, and benzene; the synthesis from benzene was the most effective. However, the nanocarbons obtained from linear molecules were more crystalline than those from ring molecules. Linear molecules decomposed into shorter olefins, whereas ring molecules were reconstructed in the plasma. $\mathrm{C}-\mathrm{H}$ dissociation proceeded in the saturated ring molecules, followed by conversion into unsaturated ring
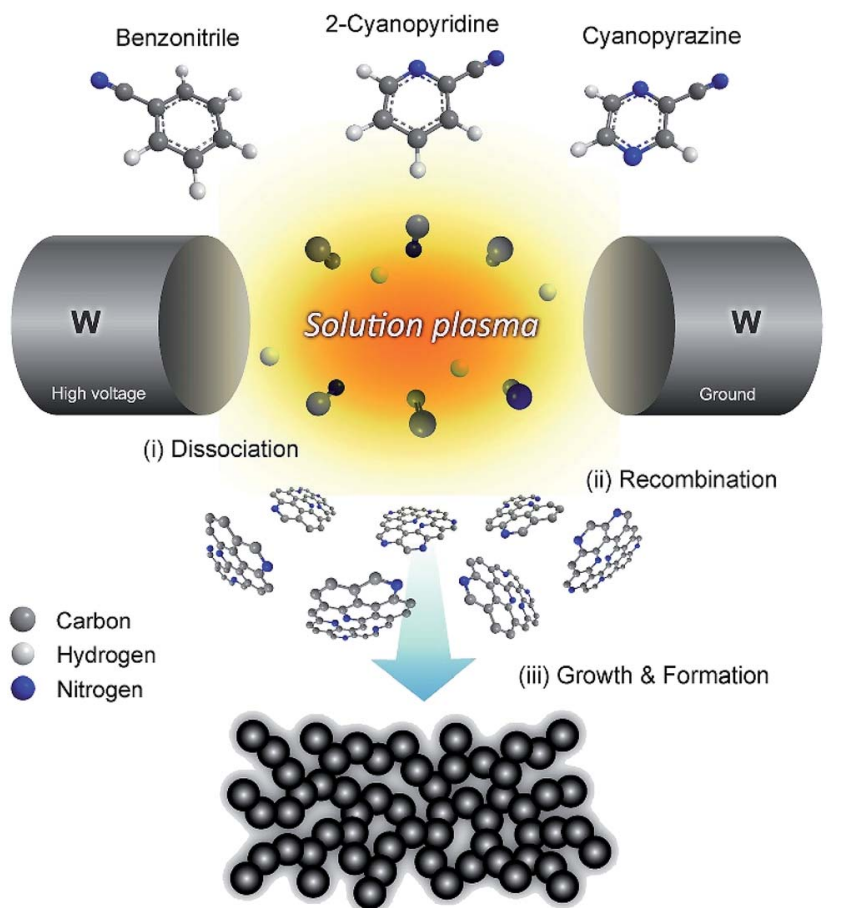

Nitrogen-doped carbon nanoparticles

Fig. 16 Schematic illustration of the formation mechanism of nitrogen-doped carbon nanoparticles (NCNPs) via a solution plasma process. Modified with permission from ref. 163. Copyright 2016 by Elsevier.

molecules. However, unsaturated ring molecules were directly polymerized through cation radicals (e.g., benzene radical cation) and were converted into two- and three-ring molecules at the plasma-solution interface. The nanocarbons from linear molecules were synthesized in plasma from small C2 molecules under heat; the products so-obtained were the same as those obtained via a pyrolysis synthesis. Conversely, the nanocarbons obtained from ring molecules were directly synthesized through an intermediate (such as benzene radical cations) at the

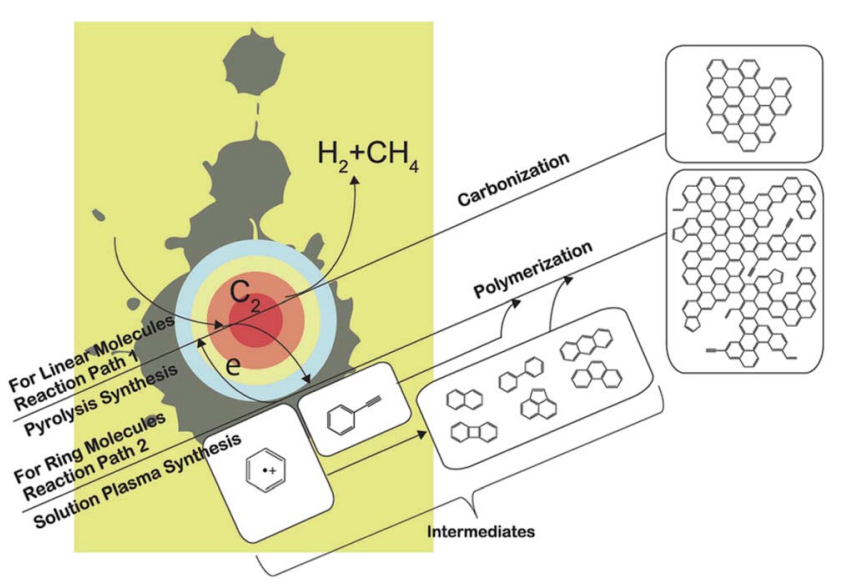

Fig. 17 Reaction routes from hexane, hexadecane, cyclohexane, and benzene. Modified with permission from ref. 164. Copyright 2016 by the Nature Publishing Group. 
interface between the plasma and the solution, resulting in the same products as those obtained via polymerization. These two different reaction fields provide a reasonable explanation for the fastest synthesis rate observed in the case of benzene. Two reaction paths from monomer to polycyclic aromatic hydrocarbons (PAHs), including graphene, are displayed in Fig. 17. One reaction path (reaction path 1 ) is from the plasma center. The solution is vaporized by a strong electric field between the electrodes. The vaporized solution forms a gas phase between the electrodes, which is converted into plasma after breakdown. In the plasma, organic compounds were almost completely decomposed, and were similar to the products obtained via a pyrolysis synthesis.

3.1.2 Quantum dots. Quantum dots are tiny particles or nanocrystals of a semiconducting material with diameters in the range of 2-10 nanometers (consisting of $c a$. 10-50 atoms), first discovered in 1980 by Ekimov and Onushchenko. ${ }^{214}$ Quantum dots display unique electronic properties that are intermediate between those of bulk semiconductors and discrete molecules, and are partly the result of unusually high surface-to-volume ratios. ${ }^{215}$

The most apparent result of this is the distinctive colors produced owing to different sizes of the nanocrystalline particles. Because of their small size, electrons in quantum dots are confined in small space (a quantum box). When the radii of the semiconductor nanocrystals are smaller than the exciton Bohr radius (exciton Bohr radius is the average distance between the electron in the conduction band and the hole it leaves behind in the valence band), the energy levels are quantized as per Pauli's exclusion principle. Because of the high level of control possible over the size of the nanocrystals produced, quantum dots can be tuned during the manufacturing process to emit light of various colors. ${ }^{216}$ These unique properties render quantum dots versatile in such applications as transistors, solar cells, LEDs, diode lasers, as well as in medical imaging and in quantum computing. ${ }^{217}$

Ultra-small sized (within $5 \mathrm{~nm}$ ) and monodispersed silicon quantum dots (Si QDs) are ideal candidates for Si/C nanocomposites to be used as anode materials in lithium ion batteries. However, fabrication of these $\mathrm{Si}$ QDs/C nanocomposites remains a gigantic challenge in materials chemistry because of the small size, high chemical activity, and low density of Si QDs with Si-H terminated surfaces. Nonetheless, Wei and coworkers ${ }^{218}$ reported a convenient synthetic method for the preparation of Si QDs/C nanocomposites by a novel liquid-phase plasma-assisted synthetic process, with the $\mathrm{Si}$ quantum dots embedded in a carbon matrix (Si-QDs/C) via a direct discharge between two electrodes powered by an AC power supply. Fig. 18a shows the setup for the liquid-phase plasma synthetic route. ${ }^{218}$ Briefly, the copper and the tungsten (with a quartz shell) electrodes were placed into an ethanol solution containing Si QDs (photograph (i)). After a $20 \mathrm{~min}$ continuous sparking discharge, grey Si QDs/C composites were obtained successfully (photograph (ii)). Photograph (iii) shows the spark during the tungsten electrode discharging process. Fig. 18b displays the TEM image of the Si QDs, revealing a diameter within $5 \mathrm{~nm}$ and a single crystalline nature with
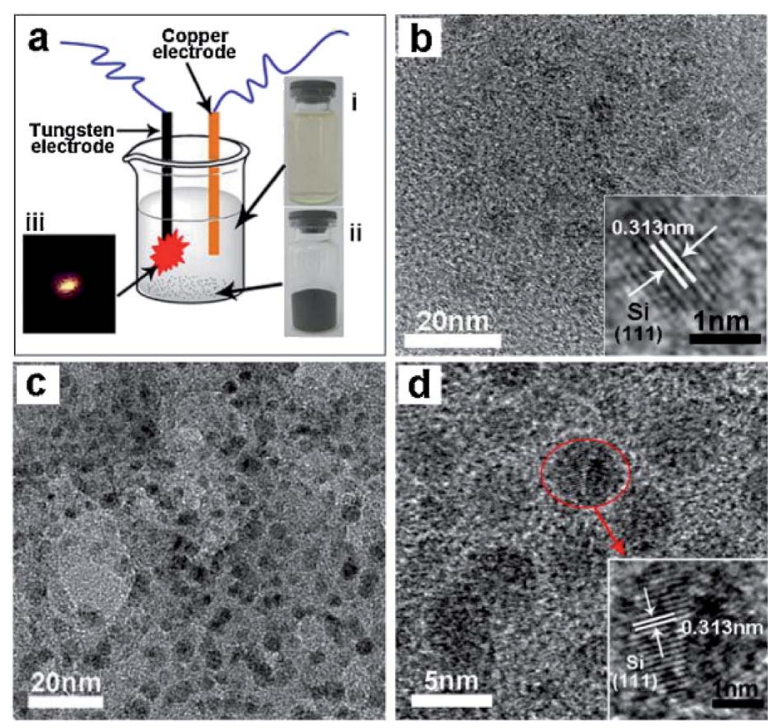

Fig. 18 (a) Setup scheme for the synthetic route. (b) TEM and HRTEM images of Si-quantum dots. (c) TEM image of the Si-quantum dots/C nano-composites. (d) HRTEM image of the Si quantum dots/C nanocomposites. Reproduced from Wei et al. ${ }^{218}$ Copyright 2013 by Elsevier.

a (111) spacing of about $0.313 \mathrm{~nm}$ in the Si crystal (see inset). Fig. 18c depicts the TEM image of the resulting Si QDs/C nanocomposites, and shows that the Si QDs are indeed embedded in large-sized amorphous carbon particles. The HRTEM image of the Si QDs/C nanocomposites is shown in Fig. 18d; the inset image highlights the Si QDs in the nanocomposites maintaining the good crystalline nature and confirms the lattice fringe space of $c a .0 .313 \mathrm{~nm}$ of the (111) plane of the Si crystal. The Si-QDs/C nanocomposites demonstrated high specific capacity, good cycling life and high Coulombic efficiency as anode materials in lithium ion batteries.

\subsection{Wastewater treatments}

In-liquid plasma techniques in wastewater treatments are associated with the formation of a light emitting plasma around an electrode in a high conductivity electrolyte solution at moderate voltages up to $1 \mathrm{kV}$. In recent years, these techniques have attracted considerable interest as a tool for generating a large quantity of heat and a high yield of solvent-split radicals. ${ }^{219}$ There are several variations of using in-liquid plasma in the treatment of wastewaters: (A) immersing the electrodes in the waters (Fig. 19a), (B) using a water flow (Fig. 19b), and (C) using bubbles (Fig. 19c) that can be roughly divided into three groups. ${ }^{220}$ In method (A) - i.e., in an underwater streamer discharge - to the extent that plasma is generated directly in the liquid, it is suitable for treating wastewaters by means of the resulting shock waves and the generated oxidative active species (e.g., 'OH radicals and ozone). Application studies have treated large quantities of water such as: ballast water, river waters, and dams from high concentrations to smaller scales. ${ }^{221}$ On the other hand, in methods (B) and (C), since the gas is converted to plasma and is introduced into the liquid, the advantage here is that plasma can be generated easily while concurrently getting 

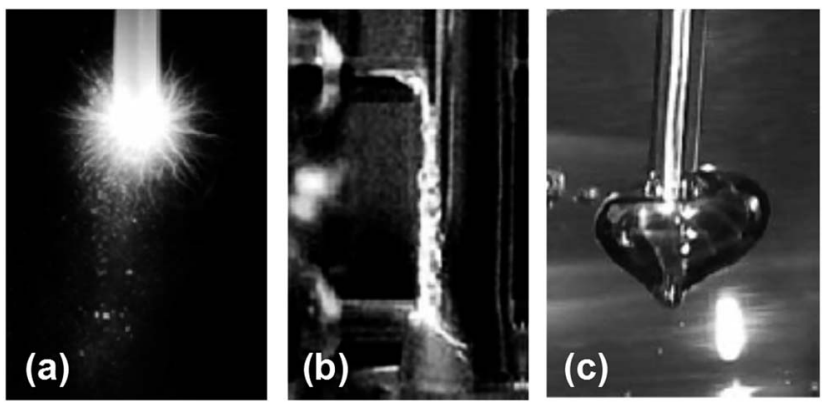

Fig. 19 Method of generating in-liquid plasma for use in water treatment: (a) method of the immersed electrodes in water; (b) method using water flow; (c) method using bubbles. Reproduced from Akiyama et al. ${ }^{220}$ Copyright 2014 by The Japan Society of Plasma Science and Nuclear Fusion Research.

significant energy saving. These systems generate plasma in bubbles and generate oxidized active species by diffusing them in water as compared with a system in which plasma is directly generated in an aqueous solution. However, compared with method (A), the number of generated ${ }^{\circ} \mathrm{OH}$ radicals is reduced by about an order of magnitude, ${ }^{127}$ so that the efficiency of the water treatment is lower. For instance, in the concurrent ultrasonic/microwave in-liquid plasma generator described in Fig. 10, the electrode is immersed in the aqueous solution, bubbles are then generated by the ultrasonic waves while plasma is generated in the solution so that the quantity of ${ }^{\circ} \mathrm{OH}$ radicals generated is decreased. However, because of the cavitation effect of ultrasonic waves, the number of ${ }^{\circ} \mathrm{OH}$ generated increases such that the total concentration of ${ }^{\circ} \mathrm{OH}$ radicals produced is also increased.

Various oxidative active species are used in water treatments. Among these, the most powerful oxidative species are the ${ }^{\circ} \mathrm{OH}$ radicals. Accordingly, studies have been carried out to increase the concentration of ${ }^{\circ} \mathrm{OH}$ radicals and enhance diffusion efficiency in water in those water treatment processes that involve in-liquid plasma. ${ }^{222}$ In addition, generation of ${ }^{\circ} \mathrm{OH}$ radicals by in-liquid plasma in water and the decomposition of contaminants have also been undertaken. ${ }^{223}$ The mechanism of ${ }^{\circ} \mathrm{OH}$ radical generation by in-liquid plasma is summarized by eqn (3)-(6). Electrons $\left(\mathrm{e}^{-*}\right)$ generated by the in-liquid plasma dissociate water and lead to the formation of ${ }^{\circ} \mathrm{OH}$ radicals (eqn (3)). On the other hand, interaction of these electrons $\left(\mathrm{e}^{-*}\right.$; eqn (4)) with dissolved oxygen generates oxygen atoms in their excited $\mathrm{O}\left({ }^{1} \mathrm{D}\right)$ and ground $\mathrm{O}\left({ }^{3} \mathrm{P}\right)$ states, which ultimately generate ${ }^{\circ} \mathrm{OH}$ radicals from water (eqn (5) and (6)). ${ }^{223}$ Therefore, increasing the concentration of dissolved oxygen leads to an increase in the concentration of ${ }^{\circ} \mathrm{OH}$ species. However, as the concentration of $\mathrm{OH}$ radicals increases, their subsequent recombination may be facilitated, so that it is disadvantageous to produce too many such species; note that the recombination process depends on the diffusion conditions of the ${ }^{\circ} \mathrm{OH}$ radical species.

$$
\mathrm{e}^{-*}+\mathrm{H}_{2} \mathrm{O} \rightarrow \mathrm{e}^{-}+{ }^{\cdot} \mathrm{OH}+\mathrm{H}^{\cdot}
$$

$$
\begin{gathered}
\mathrm{e}^{-*}+\mathrm{O}_{2} \rightarrow \mathrm{e}^{-}+\mathrm{O}\left({ }^{1} \mathrm{D}\right)+\mathrm{O}\left({ }^{3} \mathrm{P}\right) \\
\mathrm{O}\left({ }^{1} \mathrm{D}\right)+\mathrm{H}_{2} \mathrm{O} \rightarrow 2 \mathrm{OH}^{\cdot} \\
\mathrm{O}\left({ }^{3} \mathrm{P}\right)+\mathrm{H}_{2} \mathrm{O} \rightarrow 2 \mathrm{OH}^{\cdot}
\end{gathered}
$$

3.2.1 Degradation of persistent organic pollutants (POPs). Among the many fluorinated organic compounds, perfluorooctanoic acid (PFOA: $\mathrm{C}_{7} \mathrm{~F}_{15} \mathrm{COOH}$ ) and perfluorooctanesulfonic acid (PFOS: $\mathrm{C}_{8} \mathrm{~F}_{17} \mathrm{SO}_{3} \mathrm{H}$ ) possess such excellent chemical and physical characteristics as water repellence, surface-active properties, heat resistance, and chemical resistance. Consequently, they have been used widely as industrial surfactants. However, from the viewpoint of environmental persistence, bioaccumulation and toxicity they are designated as regulated substances by the Stockholm convention (persistent organic pollutants (POPs) convention). Nonetheless, even though PFOS is an alternative albeit difficult surfactant in some industries, its use is exceptionally being permitted; treatment methods to dispose of PFOS have been investigated by Schroder and Maesters ${ }^{224}$ who noted that PFOA and PFOS are difficult to decompose with ${ }^{\circ} \mathrm{OH}$ radicals and ozone. Successful methods to decompose these fluorinated substrates have involved: (i) photochemical decomposition using a photocatalyst, ${ }^{225}$ (ii) photolysis by $185 \mathrm{~nm}$ vacuum UV light, ${ }^{226}$ (iii) sulfuric acid radicals $\left(\mathrm{SO}_{4}{ }^{-\bullet}\right){ }^{227}$ (iv) a mechanochemical method, ${ }^{228}$ and (v) ultrasonic cavitation. ${ }^{229}$

Horikoshi et al. ${ }^{156}$ achieved successful decomposition of perfluorooctanoic acid (PFOA) in ion-exchange water using inliquid plasma. The methodology involved concurrent ultrasonic/microwave irradiation in an in-liquid plasma type generator; results are reported in Fig. 20.

Plasma irradiation of PFOA $(0.01 \mathrm{mM})$ in aqueous media for $90 \mathrm{~s}$ led to $59 \%$ defluorination accompanying the decomposition of PFOA, a substrate noted above as being difficult to decompose even with ${ }^{\circ} \mathrm{OH}$ radicals. Nonetheless, PFOA was decomposed synergistically by the cavitation effect generated by

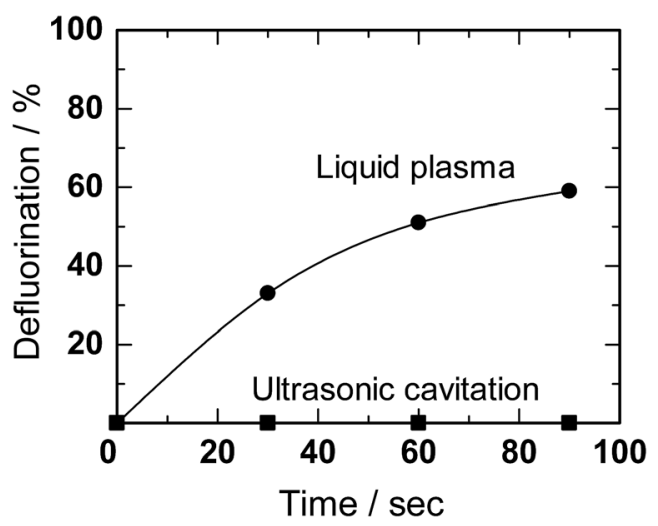

Fig. 20 Defluorination yields (\%) from the degradation of aqueous PFOA solutions $(0.01 \mathrm{mM})$ by ultrasonic cavitation alone and by the microwave discharge in-liquid plasma method under simultaneous ultrasonic cavitation (MW power, $220 \mathrm{~W}$; power for cavitation, $90 \mathrm{~W}$ ). Reproduced from Horikoshi et al. ${ }^{156}$ Copyright 2017 by Elsevier. 


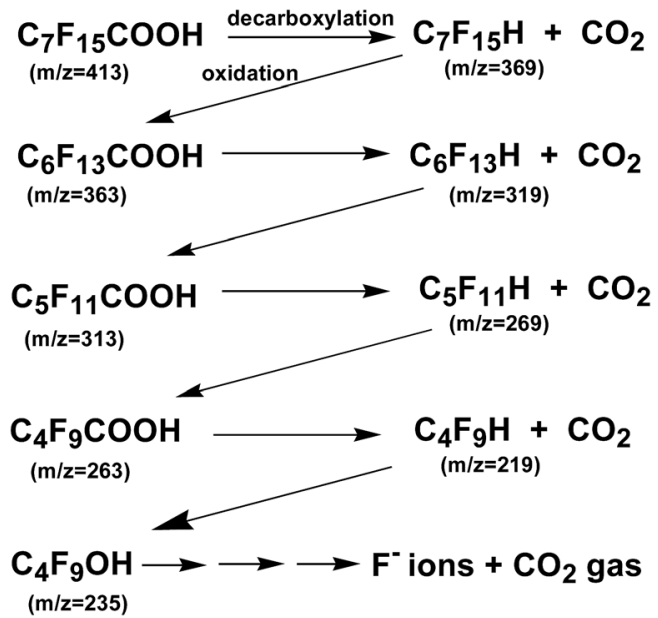

Scheme 1 Sequential loss of $\mathrm{CF}_{2}$ units from the PFOA perfluorinated acid and decarboxylated intermediates produced during the degradation of PFOA by plasma irradiation for $90 \mathrm{~s}$. Note that loss of $\mathrm{CF}_{2}$ units after the first decarboxylation step likely occurs by oxidation of the protonated terminal carbon and formation of $\mathrm{F}^{-}$ions and $\mathrm{CO}_{2}$ and so on in the Z-type pathway shown above. From Horikoshi and coworkers. ${ }^{156}$ Copyright 2017 by Elsevier.

the homogenizer in addition to the local heat and shock waves generated by the in-liquid plasma. Monitoring the decomposition of PFOA by liquid chromatography/mass spectrometry (LCMS) revealed a peak for PFOA at $m / z=413$ that decreased in intensity (thus, decomposition of PFOA) and formation of intermediates whose peak intensities at $\mathrm{m} / \mathrm{z}=363,313,263$ increased. Assigning these peaks to the various intermediates revealed that the decomposition of PFOA progressed through a gradual release of $-\mathrm{CF}_{2}$ - units (Scheme 1). Complete mineralization of PFOA to $\mathrm{CO}_{2}$ gas and $\mathrm{F}^{-}$ions was achieved. ${ }^{156}$

3.2.2 Sterilization of water by in-liquid plasma. Basic research on the sterilization of water with in-liquid plasma is being carried out quite proactively. The effects of in-liquid plasma are expected to be thermal effects in addition to those effects emanating from the generated oxidative active species ( ${ }^{\circ} \mathrm{OOH}$ and ${ }^{\circ} \mathrm{OH}$ radicals). As an example, the effect of culture temperature of Escherichia coli on pulsed electric field (PEF) sterilization has been studied by Ohshima and coworkers, ${ }^{230}$ who noted that the sterilization efficiency depends on the culture temperature of the $E$. coli bacteria and that the efficiency of PEF sterilization is influenced by the PEF treatment temperature. Moreover, insofar as the bactericidal effect of oxidative active species generated from plasmas in underwater streamer discharge liquids is concerned, sterilization is affected more by the stable hydrogen peroxide produced later in water than by the effect of ${ }^{\circ} \mathrm{OH}$ species. ${ }^{231}$

3.2.3 Hybrid in-liquid plasma/photocatalytic degradation system. Several examples exist of wastewater treatments performed with in-liquid plasma in combination with other treatment methods. For instance, synergistic effects occur in wastewater treatments using ultrasonic cavitation of activated carbon $^{232-236}$ in combination with a Fenton catalyst, ${ }^{237-243}$ with $\mathrm{TiO}_{2}$ photocatalyst particles, ${ }^{244-247}$ and $\mathrm{TiO}_{2}$ films. ${ }^{248,249}$ In

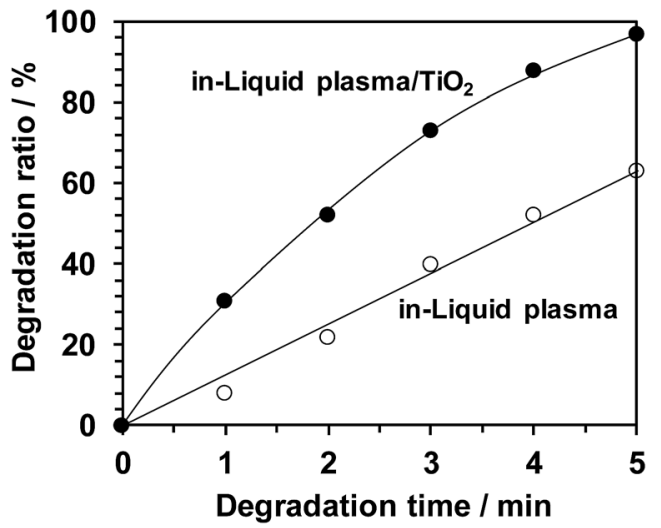

Fig. 21 Decomposition of methylene blue in aqueous solution by inliquid plasma alone and in combination with photocatalyst $\mathrm{TiO}_{2}$ particles. ${ }^{17}$ Copyright 2017 by S. Horikoshi.

addition, decomposition of dyes (e.g., methylene blue) can be achieved with an in-liquid plasma/photocatalyst system in which the $\mathrm{TiO}_{2}$ photocatalyst $(\lambda<387 \mathrm{~nm})$ was activated by the UV light emitted from the in-liquid plasma; no UV lamp was required. ${ }^{17}$ The extent of decomposition of methylene blue was $63 \%$ after a 5 min treatment by the in-liquid plasma alone; in the presence of $\mathrm{TiO}_{2}$ particulates, the decomposition of methylene blue reached $97 \%$ (see Fig. 21). The concentration of dissolved oxygen was an important factor for enhancing process efficiency. ${ }^{17}$

3.2.4 Scaled-up process. The occurrence of Microcystis aeruginosa in nature, a species of freshwater cyanobacteria that can form harmful algal blooms, is cause of some serious concerns: e.g., deterioration of the landscape, emission of a putrid odor, oxygen deficiency in water ecosystems, and not least its toxic properties that greatly affect not only the natural environment but more so the fishing industry. Accordingly, techniques to remove such species by ultrasonic waves and by shock waves (and the like) are being examined. In this regard, Sakugawa and coworkers $^{250}$ have treated Microcystis aeruginosa using in-liquid plasma; on-site demonstration experiments are also underway with a scaled-up apparatus. A demonstration experiment carried out in a vessel (width $3.9 \mathrm{~m}$, height $1.6 \mathrm{~m}$, weight $450 \mathrm{~kg}$ ) floating in a dam (see Fig. 22) and equipped with a solar cell panel and magnetic pulse compression-type in-liquid plasma generator demonstrated the self-propelled removal of Microcystis aeruginosa by the generated in-liquid plasma. ${ }^{251}$ The inliquid plasma caused the collapse of the gas bubbles inside the Microcystis aeruginosa cells triggering the buoyancy of the Microcystis aeruginosa to vanish; the treated blue patch sank into the water thus hindering the photosynthesis and suppressing any subsequent growth.

A large-sized apparatus that can process industrial wastewaters at low cost and re-use of the recycled water is being considered by the Mitsubishi Electric Co. Japan. ${ }^{252}$ Unlike existing equipment, the particular equipment being considered features wastewater treatment that can be carried out with a simple method with no chemicals involved. As such, it is characterized by low cost and no concerns with regard to secondary pollution and use of the 


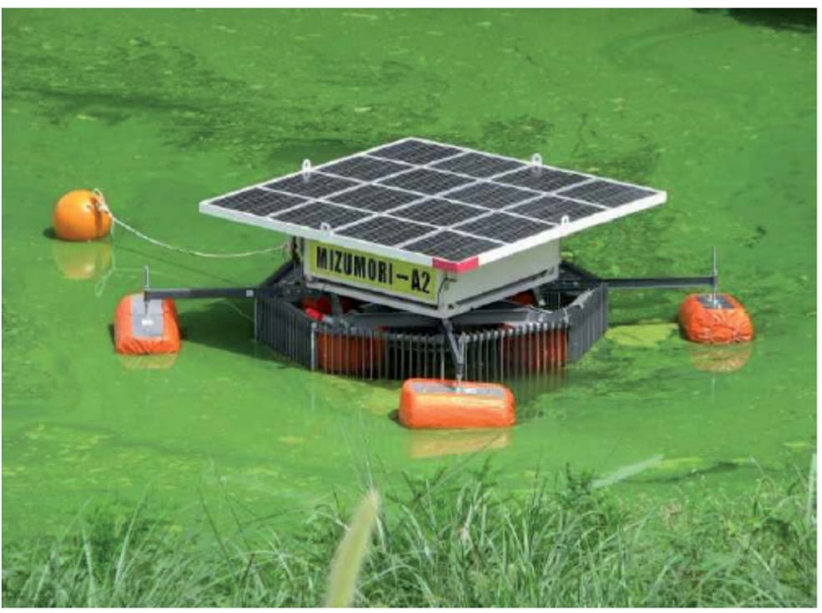

Fig. 22 Photograph of a self-propelled in-liquid plasma apparatus floating over a dam to destroy the harmful Microcystis aeruginosa. Reproduced from ref. 251. Copyright Kumamoto University, Japan

recycled waters. This equipment is expected to become an integral part of a manufacturing process.

\section{Summary remarks}

This review article has outlined and described in-liquid plasma and has provided application examples of nanomaterials synthesis and wastewater treatment. Related to the present discussion, an earlier article by Kareem and Kaliani ${ }^{253}$ reviewed the glow discharge plasma electrolytic technique for nanoparticles synthesis, while Chen et al. ${ }^{254}$ provided a theoretical analysis of the nanomaterial synthetic process from a physics point of view, and most recently Rumbach and $\mathrm{Go}^{255}$ provided a perspectives article on plasmas. It is clear from the literature that compared to gas and solid plasmas the in-liquid plasma technique has yet to fully mature from a physical and engineering viewpoints. In addition, because it has yet to be fully developed exploitation of in-liquid plasma toward new chemical processes is highly desirable without being bound to some fixed concept of the past. Accordingly, in-liquid plasma is a field filled with many possibilities and consequently should trigger the discovery of innovative processes and products.

\section{Conflicts of interest}

Authors declare no conflicts of interest.

\section{Acknowledgements}

This article would not have been possible without the fruitful collaboration of many University and industrial collaborators, and not least without the cooperation of many students whose names appear in many of the earlier publications; we are indeed grateful to them. We also wish to thank Dr S. Sato of the Saitama Institute of Technology (Japan) for the opportunity to further our interest in and appreciation of in-liquid plasma. We are also grateful to the Japan Society for the Promotion of Science (JSPS) for financial support to SH through a Grant-in-aid for Scientific Research (No. C-25420820). Financial support from the Sophia University-wide Collaborative Research Fund to $\mathrm{SH}$ is also appreciated. One of us (NS) thanks Professor Angelo Albini of the University of Pavia (Italy) for his continued hospitality during the many winter semesters in his PhotoGreen Laboratory.

\section{Notes and references}

1 S. Horikoshi, R. F. Schiffmann, J. Fukushima and N. Serpone, Microwave Chemical and Materials Processing: A Tutorial, Springer, Japan, 2017, in press.

2 I. Rahim, S. Nomura, S. Mukasa and H. Toyota, Decomposition of methane hydrate for hydrogen production using microwave and radio frequency in-liquid plasma methods, Appl. Therm. Eng., 2015, 90, 120-126.

3 A. Piel, Plasma Physics: An Introduction to Laboratory, Space, and Fusion Plasmas, Springer-Verlag, Berlin Heidelberg, 2010.

$4 \mathrm{~W}$. Crookes, On a fourth state of matter, Proc. R. Soc. London, 1879, 30, 469-472.

5 J. J. Thomson, Cathode rays, London Edinburgh Dublin, Philos. Mag., 1897, 44, 293-316.

6 I. Langmuir, Oscillations in ionized gases, Proc. Natl. Acad. Sci. U. S. A., 1928, 14, 627-637.

7 R. Itatani, Progress of plasma physics in $20^{\text {th }}$ century and future, Appl. Phys. Express, 2000, 69, 971-977.

8 M. Laroussi, Sterilization of contaminated matter with an atmospheric pressure plasma, IEEE Trans. Plasma Sci., 1996, 24, 1188-1191.

9 R. J. Goldston and P. H. Rutherford, Introduction to plasma physics, Taylor \& Francis, New York, 1995, ch. 1.

10 See: https://ia902704.us.archive.org/31/items/onradiant matterl00croorich/onradiantmatterl00croorih.pdf, accessed August 2017.

11 S. Horikoshi and N. Serpone, Microwaves in Nanoparticle Synthesis - Fundamentals and Applications, ed. S. Horikoshi and N. Serpone, Wiley-VCH, Weinheim, Germany, 2013, ch. 1.

12 J. S. Clements, M. Sato and R. H. Davis, Preliminary investigation of pre-breakdown phenomena and chemical reactions using a pulsed high-voltage discharge in water, IEEE Trans. Ind. Appl., 1987, IA-23, 224-235.

13 J. C. Devins, S. J. Rzad and R. J. Schwabe, Breakdown and pre-breakdown phenomena in liquids, J. Appl. Phys., 1981, 52, 4531-4545.

14 K. Yasukoka, T. Haehara, J. Katsuki, S. Katsuki, T. Namihira, T. Kaneko and R. Hatakeyama, Generation of underwater discharge plasma and its property, $J$. Plasma Fusion Res., 2008, 84, 666-673.

15 K. Schoenbach, J. Kolb, S. Xiao, S. Katsuki, Y. Minamitani and R. Joshi, Electrical breakdown of water in microgaps, Plasma Sources Sci. Technol., 2008, 17, 024010.

16 T. Namihira, S. Sakai, T. Yamaguchi, K. Yamamoto, C. Yamada, T. Kiyan, T. Sakugawa and S. Katsuki, Electron temperature and electron density of underwater 
pulsed discharge plasma produced by solid-state pulsedpower generator, IEEE Trans. Plasma Sci., 2007, 35, 614-618. 17 S. Horikoshi et al., to be submitted for publication in 2017. 18 G. Harrison, Wavelength tables: Wavelength by Element, MIT Press, 1982, vol. 2.

19 D. Mariotti, J. Patel, V. Švrček and P. Maguire, Plasmaliquid interactions at atmospheric pressure for nanomaterials synthesis and surface engineering, Plasma Processes Polym., 2012, 9, 1074-1085.

20 A. Hickling and M. D. Ingram, Contact glow-discharge electrolysis, Trans. Faraday Soc., 1964, 60, 783-793.

21 T. Tsuji, T. Mizuki, S. Ozono and M. Tsuji, Laser-induced silver nanocrystal formation in polyvinylpyrrolidone solutions, J. Photochem. Photobiol., A, 2009, 206, 134-139.

22 I. B. Gornushkin and U. Panne, Radiative models of laserinduced plasma and pump-probe diagnostics relevant to laser-induced breakdown spectroscopy, Spectrochim. Acta, Part B, 2000, 65, 345-359.

23 G. Saito and T. Akiyama, Nanomaterial synthesis using plasma generation in liquid, J. Nanomater., 2015, 2015, 121.

24 Y.-B. Xie and C.-J. Liu, Stability of ionic liquids under the influence of glow discharge plasmas, Plasma Processes Polym., 2008, 5, 239-245.

25 Z. Wei and C.-J. Liu, Synthesis of monodisperse gold nanoparticles in ionic liquid by applying room temperature plasma, Mater. Lett., 2011, 65, 353-355.

26 Y. Xie, Z. Wei, C.-J. Liu, L. Cui and C. Wang, Morphologic evolution of $\mathrm{Au}$ nanocrystals grown in ionic liquid by plasma reduction, J. Colloid Interface Sci., 2012, 374, 40-44.

27 Z. Wang, C.-J. Liu and G. Zhang, Size control of carbon black supported platinum nanoparticles via novel plasma reduction, Catal. Commun., 2009, 10, 959-962.

28 X. Liang, Z.-J. Wang and C.-J. Liu, Size-controlled synthesis of colloidal gold nanoparticles at room temperature under the influence of glow discharge, Nanoscale Res. Lett., 2010, 5, 124-129.

29 R. Molina, C. Ligero, P. Jovančić and E. Bertran, In situ polymerization of aqueous solutions of NIPAAm initiated by atmospheric plasma treatment, Plasma Processes Polym., 2013, 10, 506-516.

30 A. Ananth and Y. S. Mok, "Synthesis of $\mathrm{RuO}_{2}$ nanomaterials under dielectric barrier discharge plasma at atmospheric pressure - influence of substrates on the morphology and application, Chem. Eng. J., 2014, 239, 290-298.

31 K. Kitano, H. Aoki and S. Hamaguchi, Radio-frequency driven atmospheric-pressure plasmas in contact with liquid water, Jpn. J. Appl. Phys., Part 1, 2006, 45, 8294-8297.

32 E. Acayanka, A. T. Djowe, S. Laminsi, C. C. Tchoumkwé, S. Nzali, A. P. Mbouopda, P. T. Ndifon and E. M. Gaigneaux, Plasma-assisted synthesis of $\mathrm{TiO}_{2}$ nanorods by gliding arc discharge processing at atmospheric pressure for photocatalytic applications, Plasma Chem. Plasma Process., 2013, 33, 725-735.

33 T. Kaneko, K. Baba, T. Harada and R. Hatakeyama, Novel gas-liquid interfacial plasmas for synthesis of metal nanoparticles, Plasma Processes Polym., 2009, 6, 713-718.
34 T. Kaneko, K. Baba and R. Hatakeyama, Static gas-liquid interfacial direct current discharge plasmas using ionic liquid cathode, J. Appl. Phys., 2009, 105, 103306.

35 K. Baba, T. Kaneko and R. Hatakeyama, Efficient synthesis of gold nanoparticles using ion irradiation in gas-liquid interfacial plasmas, Appl. Phys. Express, 2009, 2, 035006.

36 K. Baba, T. Kaneko, R. Hatakeyama, K. Motomiya and K. Tohji, Synthesis of monodispersed nanoparticles functionalized carbon nanotubes in plasma-ionic liquid interfacial fields, Chem. Commun., 2010, 46, 255-257.

37 T. Kaneko, Q. Chen, T. Harada and R. Hatakeyama, Structural and reactive kinetics in gas-liquid interfacial plasmas, Plasma Sources Sci. Technol., 2011, 20, 034014.

38 Q. Chen, T. Kaneko and R. Hatakeyama, Rapid synthesis of water-soluble gold nanoparticles with control of size and assembly using gas-liquid interfacial discharge plasma, Chem. Phys. Lett., 2012, 521, 113-117.

39 Q. Chen, T. Kaneko and R. Hatakeyama, Characterization of pulse-driven gas-liquid interfacial discharge plasmas and application to synthesis of gold nanoparticle-DNA encapsulated carbon nanotubes, Curr. Appl. Phys., 2011, 11, S63-S66.

40 S. A. Meiss, M. Rohnke, L. K. P. Doz, S. Z. E. Abedin, F. Endres and J. Janek, Employing plasmas as gaseous electrodes at the free surface of ionic liquids: deposition of nanocrystalline silver particles, ChemPhysChem, 2007, 8, 50-53.

41 M. Brettholle, O. Höfft, L. Klarhöfer, S. Mathes, W. MausFriedrichs, S. Z. E. Abedin, S. Krischok, J. Janekd and F. Endres, Plasma electrochemistry in ionic liquids: deposition of copper nanoparticles, Phys. Chem. Chem. Phys., 2010, 12, 1750-1755.

42 O. Höfft and F. Endres, Plasma electrochemistry in ionic liquids: an alternative route to generate nanoparticles, Phys. Chem. Chem. Phys., 2011, 13, 13472.

43 N. Kulbe, O. Höfft, A. Ulbrich, S. Z. E. Abedin, S. Krischok, J. Janekd, M. Pölleth and F. Endres, Plasma electrochemistry in 1-butyl-3-methyl-imidazolium dicyanamide: copper nano-particles from $\mathrm{CuCl}$ and $\mathrm{CuCl}_{2}$, Plasma Processes Polym., 2011, 8, 32-37.

44 F. Yang, Y. Li, T. Liu, K. Xu, L. Zhang, C. Xu and J. Gao, Plasma synthesis of Pd nanoparticles decorated-carbon nanotubes and its application in Suzuki reaction, Chem. Eng. J., 2013, 226, 52-58.

45 T. Liu, F. Yang, Y. Li, L. Ren, L. Zhang, K. Xu, X. Wang, C. Xu and J. Gao, Plasma synthesis of carbon nanotube-gold nanohybrids: efficient catalysts for green oxidation of silanes in water, J. Mater. Chem., 2014, 2, 245-250.

46 C. Sugama, F. Tochikubo and S. Uchida, Glow discharge formation over water surface at saturated water vapor pressure and its application to wastewater treatment, Jpn. J. Appl. Phys., Part 1, 2006, 45, 8858-8863.

47 A. Hickling and M. D. Ingram, Glow-discharge electrolysis, J. Electroanal. Chem., 1964, 8, 65-81.

$48 \mathrm{H}$. Kawamura, K. Moritani and Y. Ito, Discharge electrolysis in molten chloride: formation of fine silver particles, Plasmas Ions, 1998, 1, 29-36. 
49 M. Tokushige, T. Nishikiori and Y. Ito, Plasma-induced cathodic discharge electrolysis to form various metal/alloy nanoparticles, Russ. J. Electrochem., 2010, 46, 619-626.

50 M. Tokushige, H. Tsujimura, T. Nishikiori and Y. Ito, Formation of metallic $\mathrm{Si}$ and $\mathrm{SiC}$ nanoparticles from $\mathrm{SiO}_{2}$ particles by plasma-induced cathodic discharge electrolysis in chloride melt, Electrochim. Acta, 2013, 100, 300-303.

51 M. Tokushige, T. Yamanaka, A. Matsuura, T. Nishikiori and Y. Ito, Synthesis of magnetic nanoparticles (Fe and FePt) by plasma-induced cathodic discharge electrolysis, IEEE Trans. Plasma Sci., 2009, 37, 1156-1160.

52 M. Tokushige, T. Nishikiori and Y. Ito, Formation of fine Ni nanoparticle by plasma-induced cathodic discharge electrolysis using rotating disk anode, J. Electrochem. Soc., 2010, 157, E162-E166.

53 M. Tokushige, T. Nishikiori and Y. Ito, Synthesis of Ni nanoparticles by plasma-induced cathodic discharge electrolysis, J. Appl. Electrochem., 2009, 39, 1665-1670.

54 M. Tokushige, H. Hongo, T. Nishikiori and Y. Ito, Formation of Sm-Co intermetallic compound nanoparticles based on plasma-induced cathodic discharge electrolysis in chloride melt, J. Electrochem. Soc., 2012, 159, E5-E10.

55 M. Tokushige, T. Nishikiori, M. C. Lafouresse, C. Michiokad, K. Yoshimurad, Y. Fukunakac and Y. Ito, Formation of FePt intermetallic compound nanoparticles by plasma induced cathodic discharge electrolysis, Electrochim. Acta, 2010, 55, 8154-8159.

56 P. Bruggeman, E. Ribězl, J. Degroote, J. Vierendeels and C. Leys, Plasma characteristics and electrical breakdown between metal and water electrodes, J. Optoelectron. Adv. Mater., 2008, 10, 1964-1967.

57 W.-T. Yao, S.-H. Yu, Y. Zhou, J. Jiang, Q.-S. Wu, L. Zhang and J. Jiang, Formation of uniform $\mathrm{CuO}$ nanorods by spontaneous aggregation: selective synthesis of $\mathrm{CuO}$, $\mathrm{Cu}_{2} \mathrm{O}$, and $\mathrm{Cu}$ nanoparticles by a solid-liquid phase arc discharge process, J. Phys. Chem. B, 2005, 109, 14011-14016.

58 K. Furuya, Y. Hirowatari, T. Ishioka and A. Harata, Protective agent-free preparation of gold nanoplates and nanorods in aqueous $\mathrm{HAuCl}_{4}$ solutions using gas-liquid interface discharge, Chem. Lett., 2007, 36, 1088-1089.

59 M. Ito, M. Hayakawa, S. Takashima, E. Asami, T. Aoki, M. Oka, H. Asano, M. Kitahara, S. Nakata and K. Yamaguchi, Preparation of aqueous dispersion of titanium dioxide nanoparticles using plasma on liquid surface, Jpn. J. Appl. Phys., 2012, 51, 116201.

60 T. Hagino, H. Kondo, K. Ishikawa, H. Kano, M. Sekine and M. Hori, Ultrahigh-speed synthesis of nanographene using alcohol in-liquid plasma, Appl. Phys. Express, 2012, 5, 035101.

61 M. Matsushima, M. Noda, T. Yoshida, H. Kato, G. Kalita, T. Kizuki, H. Uchida, M. Umeno and K. Wakita, Formation of graphene nano-particle by means of pulsed discharge to ethanol, J. Appl. Phys., 2013, 113, 114304.
62 D. Kozak, E. Shibata, A. Iizuka and T. Nakamura, Growth of carbon dendrites on cathode above liquid ethanol using surface plasma, Carbon, 2014, 70, 87-94.

63 M. Tokushige, A. Matsuura, T. Nishikiori and Y. Ito, Formation of Co-Pt intermetallic compound nanoparticles by plasma induced cathodic discharge electrolysis in a chloride melt, J. Electrochem. Soc., 2011, 158, E21-E26.

64 Y. Hayashi, S. Machmudah, N. Takada, H. Kanda, K. Sasaki and M. Goto, Decomposition of methyl orange using pulsed discharge plasma at atmospheric pressure: effect of different electrodes, Jpn. J. Appl. Phys., 2014, 53, 010212.

65 I. G. Koo, M. S. Lee, J. H. Shim, J. H. Ahn and W. M. Lee, Platinum nanoparticles prepared by a plasma-chemical reduction method, J. Mater. Chem., 2005, 15, 4125-4128.

66 C. Richmonds and R. M. Sankaran, Plasma-liquid electrochemistry: rapid synthesis of colloidal metal nanoparticles by microplasma reduction of aqueous cations, Appl. Phys. Lett., 2008, 93, 131501.

67 N. Shirai, M. Nakazawa, S. Ibuka and S. Ishii, Atmospheric DC glow microplasmas using miniature gas flow and electrolyte cathode, Jpn. J. Appl. Phys., 2009, 48, 036002.

68 F.-C. Chang, C. Richmonds and R. M. Sankaran, Microplasma-assisted growth of colloidal Ag nanoparticles for point of-use surface-enhanced Raman scattering applications, J. Vac. Sci. Technol., A, 2010, 28, L5.

69 V. Svrcek, D. Mariotti and M. Kondo, Microplasma-induced surface engineering of silicon nanocrystals in colloidal dispersion, Appl. Phys. Lett., 2010, 97, 161502.

70 W.-H. Chiang, C. Richmonds and R. M. Sankaran, Continuous-flow, atmospheric-pressure microplasmas: aversatile source for metal nanoparticle synthesis in the gas or liquid phase, Plasma Sources Sci. Technol., 2010, 19, 034011.

71 X. Z. Huang, X. X. Zhong, Y. Lu, Y. Li, A. E. Rider, S. A. Furman and K. Ostrikov, Plasmonic Ag nanoparticles via environment-benign atmospheric microplasma electrochemistry, Nanotechnology, 2013, 24, 095604.

72 J. Patel, L. Němcová, P. Maguire, W. G. Graham and D. Mariotti, Synthesis of surfactant-free electrostatically stabilized gold nanoparticles by plasma-induced liquid chemistry, Nanotechnology, 2013, 24, 245604.

$73 \mathrm{C}$. Du and M. Xiao, $\mathrm{Cu}_{2} \mathrm{O}$ nanoparticles synthesis by microplasma, Sci. Rep., 2014, 4, 7339-7344.

74 R. Wang, S. Zuo, D. Wu, J. Zhang, W. Zhu, K. H. Becker and J. Fang, Microplasma-assisted synthesis of colloidal gold nanoparticles and their use in the detection of cardiac troponin I (cTn-I), Plasma Processes Polym., 2015, 12, 380391.

75 T. Yan, X. Zhong, A. E. Rider, Y. Lu, S. A. Furman and K. Ostrikov, Microplasma-chemical synthesis and tunable real time plasmonic responses of alloyed $\mathrm{Au}_{\mathrm{x}} \mathrm{Ag}_{1-\mathrm{x}}$ nanoparticles, Chem. Commun., 2014, 50, 3144-3147.

76 N. Shirai, S. Uchida and F. Tochikubo, Synthesis of metal nanoparticles by dual plasma electrolysis using atmospheric de glow discharge in contact with liquid, Jpn. J. Appl. Phys., 2014, 53, 046202. 
77 B. Sun, M. Sato and J. S. Clements, Optical study of active species produced by a pulsed streamer corona discharge in water, J. Electrost., 1997, 39, 189-202.

78 P. Bruggeman, T. Verreycken, M. Á. Gonález, J. L. Walsh, M. G. Kong, C. Leys and D. C. Schram, Optical emission spectroscopy as a diagnostic for plasmas in liquids: opportunities and pitfalls, J. Phys. D: Appl. Phys., 2010, 43, 124005.

79 Q. Chen, T. Kitamura, K. Saito, K. Haruta, Y. Yamano, T. Ishikawa and $\mathrm{H}$. Shirai, Microplasma discharge in ethanol solution: characterization and its application to the synthesis of carbon microstructures, Thin Solid Films, 2008, 516, 4435-4440.

80 K. Greda, P. Jamroz and P. Pohl, Effect of the addition of nonionic surfactants on the emission characteristic of direct current atmospheric pressure glow discharge generated in contact with a flowing liquid cathode, $J$. Anal. At. Spectrom., 2012, 28, 134-141.

81 P. Jamroz, K. Greda and P. Pohl, Development of direct current, atmospheric-pressure, glow discharges generated in contact with flowing electrolyte solutions for elemental analysis by optical emission spectrometry, TrAC, Trends Anal. Chem., 2012, 41, 105-121.

82 P. Jamróz, P. Pohl and W. Zyrnicki, An analytical performance of atmospheric pressure glow discharge generated in contact with flowing small size liquid cathode, J. Anal. At. Spectrom., 2012, 27, 1032-1037.

83 K. Greda, P. Jamroz and P. Pohl, Comparison of the performance of direct current atmospheric pressure glow microdischarges operated between a small sized flowing liquid cathode and miniature argon or helium flow microjets, J. Anal. At. Spectrom., 2013, 28, 1233-1241.

84 K. Greda, P. Jamroz, A. Dzimitrowicz and P. Pohl, Direct elemental analysis of honeys by atmospheric pressure glow discharge generated in contact with a flowing liquid cathode, J. Anal. At. Spectrom., 2014, 30, 154-161.

85 S. A. Campbell, V. J. Cunnane and D. J. Schiffrin, Cathodic contact glow discharge electrolysis under reduced pressure, J. Electroanal. Chem., 1992, 325, 257-268.

86 A. Lal, H. Bleuler and R. Wüthrich, Fabrication of metallic nanoparticles by electrochemical discharges, Electrochem. Commun., 2008, 10, 488-491.

87 Y. Zhou, S. H. Yu, X. P. Cui, G. Y. Wang and Z. Y. Chen, Formation of silver nanowires by a novel solid-liquid phase arc discharge method, Chem. Mater., 1999, 11, 545546.

88 Y. Toriyabe, S. Watanabe, S. Yatsu, T. Shibayama and T. Mizuno, Controlled formation of metallic nanoballs during plasma electrolysis, Appl. Phys. Lett., 2007, 91, 041501.

89 G. Saito, S. Hosokai, T. Akiyama, S. Yoshida, S. Yatsu and S. Watanabe, Size-controlled Ni nanoparticles formation by solution glow discharge, J. Phys. Soc. Jpn., 2010, 79, 083501.

90 G. Saito, S. Hosokai and T. Akiyama, Synthesis of ZnO nanoflowers by solution plasma, Mater. Chem. Phys., 2011, 130, 79-83.
91 G. Saito, S. Hosokai, M. Tsubota and T. Akiyama, Nickel nanoparticles formation from solution plasma using edge shielded electrode, Plasma Chem. Plasma Process., 2011, 31, 719-728.

92 G. Saito, S. Hosokai, M. Tsubota and T. Akiyama, Synthesis of copper/copper oxide nanoparticles by solution plasma, $J$. Appl. Phys., 2011, 110, 023302.

93 G. Saito, S. Hosokai, M. Tsubota and T. Akiyama, "Surface morphology of a glow discharge electrode in a solution, $J$. Appl. Phys., 2012, 112, 013306.

94 G. Saito, S. Hosokai, M. Tsubota and T. Akiyama, Influence of solution temperature and surfactants on morphologies of tin oxide produced using a solution plasma technique, Cryst. Growth Des., 2012, 12, 2455-2459.

95 Z. Wu, Z.-K. Zhang, D.-Z. Guo, Y.-J. Xing and G.-M. Zhang, Titanium oxide nanospheres: preparation, characterization, and wide-spectral absorption, Phys. Status Solidi A, 2012, 209, 2020-2026.

96 A. Allagui, E. A. Baranova and R. Wüthrich, Synthesis of Ni and Pt nanomaterials by cathodic contact glow discharge electrolysis in acidic and alkaline media, Electrochim. Acta, 2013, 93, 137-142.

97 Y. Nakasugi, G. Saito, T. Yamashita and T. Akiyama, Synthesis of nonstoichiometric titanium oxide nanoparticles using discharge in $\mathrm{HCl}$ solution, J. Appl. Phys., 2014, 115, 123303.

98 G. Saito, W. O. S. B. W. M. Azman, Y. Nakasugi and T. Akiyama, Optimization of electrolyte concentration and voltage for effective formation of $\mathrm{Sn} / \mathrm{SnO}_{2}$ nanoparticles by electrolysis in liquid, Adv. Powder Technol., 2014, 25, 1038-1042.

99 G. Saito, Y. Nakasugi and T. Akiyama, Excitation temperature of a solution plasma during nanoparticle synthesis, J. Appl. Phys., 2014, 116, 083301.

100 G. Saito, Y. Nakasugi, T. Yamashita and T. Akiyama, Solution plasma synthesis of $\mathrm{ZnO}$ flowers and their photoluminescence properties, Appl. Surf. Sci., 2014, 290, 419-424.

101 G. Saito, C. Zhu and T. Akiyama, Surfactant-assisted synthesis of $\mathrm{Sn}$ nanoparticles via solution plasma technique, Adv. Powder Technol., 2014, 25, 728-732.

102 G. Saito, Y. Nakasugi, T. Yamashita and T. Akiyama, Solution plasma synthesis of bimetallic nanoparticles, Nanotechnology, 2014, 25, 135603.

103 T. Paulmier, J. M. Bell and P. M. Fredericks, Development of a novel cathodic plasma/electrolytic deposition technique. Part 2: physicochemical analysis of the plasma discharge, Surf. Coat. Technol., 2007, 201, 8771-8781.

104 J. Gao, A. Wang, Y. Li, Y. Fu, J. Wu, Y. Wang and Y. Wang, Synthesis and characterization of superabsorbent composite by using glow discharge electrolysis plasma, React. Funct. Polym., 2008, 68, 1377-1383.

105 T. Paulmier, J. M. Bell and P. M. Fredericks, Plasma electrolytic deposition of titanium dioxide nanorods and nano-particles, J. Mater. Process. Technol., 2008, 208, 117123. 
106 G. Saito, S. Hosokai, M. Tsubota and T. Akiyama, Ripple formation on a nickel electrode during a glow discharge in a solution, Appl. Phys. Lett., 2012, 100, 181601.

107 M. R. M. B. Julaihi, S. Yatsu, M. Jeem and S. Watanabe, Synthesis of stainless steel nanoballs via submerged glowdischarge plasma and its photocatalytic performance in methylene blue decomposition, J. Exp. Nanosci., 2014, 10, 965-982.

108 G. Saito and N. Sakaguchi, Solution plasma synthesis of Si nanoparticles, Nanotechnology, 2015, 26, 235602.

109 K. Azumi, A. Kanada, M. Kawaguchi and M. Seo, Formation of microparticles from titanium and silicon electrodes using high voltage discharge in electrolyte solution, Hyomen Jijutsu, 2005, 56, 938-941.

110 L. Schaper, W. G. Graham and K. R. Stalder, Vapour layer formation by electrical discharges through electrically conducting liquids-modelling and experiment, Plasma Sources Sci. Technol., 2011, 20, 034003.

111 L. Schaper, K. R. Stalder and W. G. Graham, Plasma production in electrically conducting liquids, Plasma Sources Sci. Technol., 2011, 20, 034004.

112 P. Ruma, N. Lukes, N. Aoki, E. Spetlikova, S. H. R. Hosseini, T. Sakugawa and H. Akiyama, Effects of pulse frequency of input power on the physical and chemical properties of pulsed streamer discharge plasmas in water, J. Phys. D: Appl. Phys., 2013, 46, 125202.

113 G. Saito, Y. Nakasugi and T. Akiyama, Generation of solution plasma over a large electrode surface area, $J$. Appl. Phys., 2015, 118, 023303.

114 S. Yatsu, H. Takahashf, H. Sasaki, N. Sakaguchi, K. Ohkubo, T. Muramoto and S. Watanabe, Fabrication of nanoparticles by electric discharge plasma in liquid, Arch. Metall. Mater., 2013, 58, 425-429.

115 G. Saito, Y. Nakasugi and T. Akiyama, High-speed camera observation of solution plasma during nanoparticles formation, Appl. Phys. Lett., 2014, 104, 83104.

116 K. Kobayashi, Y. Tomita and M. Sanmyo, Electrochemical generation of hot plasma by pulsed discharge in an electrolyte, J. Phys. Chem. B, 2000, 104, 6318-6326.

117 T. Mizuno, T. Akimoto, K. Azumi, T. Ohmori, Y. Aoki and A. Takahashi, Hydrogen evolution by plasma electrolysis in aqueous solution, Jpn. J. Appl. Phys., Part 1, 2005, 44, 396-401.

118 A. Hickling and M. D. Ingram, Contact glow-discharge electrolysis, Trans. Faraday Soc., 1964, 60, 783-793.

119 L. Wang, Aqueous organic dye discoloration induced by contact glow discharge electrolysis, J. Hazard. Mater., 2009, 171, 577-581.

120 Y. Liu and X. Jiang, Plasma-induced degradation of chlorobenzene in aqueous solution, Plasma Chem. Plasma Process., 2008, 28, 15-24.

121 K. Azumi, T. Mizuno, T. Akimoto and T. Ohmori, Light emission from Pt during high-voltage cathodic polarization, J. Electrochem. Soc., 1999, 146, 3374-3377.

122 S. K. Sengupta, R. Singh and A. K. Srivastava, A study on the origin of nonfaradaic behavior of anodic contact glow discharge electrolysis: the relationship between power dissipated in glow discharges and nonfaradaic yields, $J$. Electrochem. Soc., 1998, 145, 2209-2213.

123 J. Gong, J. Wang, W. Xie and W. Cai, Enhanced degradation of aqueous methyl orange by contact glow discharge electrolysis using $\mathrm{Fe}^{2+}$ as catalyst, J. Appl. Electrochem., 2008, 38, 1749-1755.

124 J. Gao, Z. Hu, X. Wang, J. Hou, X. Lu and J. Kang, Oxidative degradation of acridine orange induced by plasma with contact glow discharge electrolysis, Thin Solid Films, 2001, 390, 154-158.

125 J. Gao, X. Wang, Z. Hu, H. Deng, J. Hou, X. Lu and J. Kang, Plasma degradation of dyes in water with contact glow discharge electrolysis, Water Res., 2003, 37, 267-272.

126 J. Gao, Y. Liu, W. Yang, L. Pu, J. Yu and Q. Lu, Oxidative degradation of phenol in aqueous electrolyte induced by plasma from a direct glow discharge, Plasma Sources Sci. Technol., 2003, 12, 533-538.

127 P. Bruggeman, D. Schram, M. Á. González, R. Rego, M. G. Kong and C. Leys, Characterization of a direct dcexcited discharge in water by optical emission spectroscopy, Plasma Sources Sci. Technol., 2009, 18, 025017.

128 K.-Y. Shih and B. R. Locke, Effects of electrode protrusion length, pre-existing bubbles, solution conductivity and temperature, on liquid phase pulsed electrical discharge, Plasma Processes Polym., 2009, 6, 729-740.

129 T. Maehara, K. Nishiyama, S. Onishi, S. Mukasa, H. Toyota, M. Kuramoto, S. Nomura and A. Kawashima, Degradation of methylene blue by radio frequency plasmas in water under ultraviolet irradiation, J. Hazard. Mater., 2010, 174, 473-476.

130 S. Mukasa, T. Maehara, S. Nomura, H. Toyota, A. Kawashima, Y. Hattori, Y. Hashimoto and H. Yamashita, Growth of bubbles containing plasma in water by high-frequency irradiation, Int. J. Heat Mass Transfer, 2010, 53, 3067-3074.

131 T. Maehara, S. Honda, C. Inokuchi, M. Kuramoto, S. Mukasa, H. Toyota, S. Nomura and A. Kawashima, Influence of conductivity on the generation of a radio frequency plasma surrounded by bubbles in water, Plasma Sources Sci. Technol., 2011, 20, 034016.

132 T. Maehara, H. Toyota, M. Kuramoto, A. Iwamae, A. Tadokoro, S. Mukasa, H. I. Yamashita, A. Kawashima and S. Nomura, Radio frequency plasma in water, Jpn. J. Appl. Phys., Part 1, 2006, 45, 8864-8868.

133 T. Maehara, I. Miyamoto, K. Kurokawa, Y. Hashimoto, A. Iwamae, M. Kuramoto, H. Yamashita, S. Mukasa, H. Toyota, S. Nomura and A. Kawashima, Degradation of methylene blue by RF plasma in water, Plasma Chem. Plasma Process., 2008, 28, 467-482.

134 S. Nomura, H. Toyota, S. Mukasa, Y. Takahashi, T. Maehara, A. Kawashima and H. Yamashita, Discharge characteristics of microwave and high-frequency in-liquid plasma in water, Appl. Phys. Express, 2008, 1, 046002.

135 S. Nomura, S. Mukasa, H. Toyota, H. Miyake, H. Yamashita, T. Maehara, A. Kawashima and F. Abe, Characteristics of in liquid plasma in water under higher pressure than 
atmospheric pressure, Plasma Sources Sci. Technol., 2011, 20, 034012.

136 S. Mukasa, S. Nomura, H. Toyota, T. Maehara and H. Yamashita, Internal conditions of a bubble containing radiofrequency plasma in water, Plasma Sources Sci. Technol., 2011, 20, 034020.

137 A. Kawashima, H. Toyota, S. Nomura, T. Takemori, S. Mukasa, T. Maehara and H. Yamashita, 27.12 MHz plasma generation in supercritical carbon dioxide, J. Appl. Phys., 2007, 101, 093303.

138 T. Maehara, A. Kawashima, A. Iwamae, S. Mukasa, T. Takemori, T. Watanabe, K. Kurokawa, H. Toyota and S. Nomura, Spectroscopic measurements of high frequency plasma in supercritical carbon dioxide, Phys. Plasmas, 2009, 16, 033503.

139 A. E. E. Putra, S. Nomura, S. Mukasa and H. Toyota, Hydrogen production by radio frequency plasma stimulation in methane hydrate at atmospheric pressure, Int. J. Hydrogen Energy, 2012, 37, 16000-16005.

140 Y. Hattori, S. Nomura, S. Mukasa, H. Toyota, T. Inoue and T. Usui, Synthesis of tungsten oxide, silver, and gold nanoparticles by radio frequency plasma in water, $J$. Alloys Compd., 2013, 578, 148-152.

141 S. Mukasa, S. Nomura and H. Toyota, Observation of microwave in-liquid plasma using high-speed camera, Jpn. J. Appl. Phys., Part 1, 2007, 46, 6015-6021.

142 S. Mukasa, S. Nomura, H. Toyota, T. Maehara, F. Abe and A. Kawashima, Temperature distributions of radiofrequency plasma in water by spectroscopic analysis, $J$. Appl. Phys., 2009, 106, 113302.

143 Y. Hattori, S. Mukasa, S. Nomura and H. Toyota, Optimization and analysis of shape of coaxial electrode for microwave plasma in water, J. Appl. Phys., 2010, 107, 063305.

144 Y. Hattori, S. Mukasa, H. Toyota, T. Inoue and S. Nomura, Synthesis of zinc and zinc oxide nanoparticles from zinc electrode using plasma in liquid, Mater. Lett., 2011, 65, 188-190.

145 Y. Hattori, S. Mukasa, H. Toyota, H. Yamashita and S. Nomura, Improvement in preventing metal contamination from an electrode used for generating microwave plasma in liquid, Surf. Coat. Technol., 2012, 206, 2140-2145.

146 Y. Hattori, S. Mukasa, H. Toyota and S. Nomura, Electrical breakdown of microwave plasma in water, Curr. Appl. Phys, 2013, 13, 1050-1054.

147 Y. Hattori, S. Mukasa, H. Toyota, T. Inoue and S. Nomura, Continuous synthesis of magnesium- hydroxide, zincoxide, and silver nanoparticles by microwave plasma in water, Mater. Chem. Phys., 2011, 131, 425-430.

148 Y. Hattori, S. Nomura, S. Mukasa, H. Toyota, T. Inoue and T. Kasahara, Synthesis of tungsten trioxide nanoparticles by microwave plasma in liquid and analysis of physical properties, J. Alloys Compd., 2013, 560, 105-110.

149 H. Toyota, S. Nomura, S. Mukasa, H. Yamashita, T. Shimo and S. Okuda, A consideration of ternary $\mathrm{C}-\mathrm{H}-\mathrm{O}$ diagram for diamond deposition using microwave in-liquid and gas phase plasma, Diamond Relat. Mater., 2011, 20, 12551258.

150 T. Yonezawa, A. Hyono, S. Sato and O. Ariyada, Preparation of zinc oxide nanoparticles by using microwave-induced plasma in liquid, Chem. Lett., 2010, 39, 783-785.

151 S. Sato, K. Mori, O. Ariyada, H. Atsushi and T. Yonezawa, Synthesis of nanoparticles of silver and platinum by microwave induced plasma in liquid, Surf. Coat. Technol., 2011, 206, 955-958.

152 T. Ishijima, H. Hotta, H. Sugai and M. Sato, Multibubble plasma production and solvent decomposition in water by slot excited microwave discharge, Appl. Phys. Lett., 2007, 91, 121501.

153 S. Nomura, A. E. E. Putra, S. Mukasa, H. Yamashita and H. Toyota, Plasma decomposition of clathrate hydrates by $2.45 \mathrm{GHz}$ microwave irradiation at atmospheric pressure, Appl. Phys. Express, 2011, 4, 066201.

154 H. Toyota, S. Nomura and S. Mukasa, A practical electrode for microwave plasma processes, Int. J. Mater. Sci. Appl., 2013, 2, 83-88.

155 T. Watano, K. Kurosawa and K. Mizuno, Effect of plasmadischarge in water on wire electrode, Aichi center, Indus. Sci. Technol., 2008.

156 S. Horikoshi, S. Sato, M. Abe and N. Serpone, A novel liquid plasma AOP device integrating microwaves and ultrasounds and its evaluation in defluorinating perfluorooctanoic acid in aqueous media, Ultrason. Sonochem., 2011, 18, 938-942.

157 X. Hua, X. Shen, O. Takai and N. Saito, Facile fabrication of PtAu alloy clusters using solution plasma sputtering and their electrocatalytic activity, J. Alloys Compd., 2013, 552, 351-355.

158 See: http:/www.chusho.meti.go.jp/keiei/sapoin/portal/ seika/2010/22131318032.pdf, accessed August 2017.

159 F. Xu, Y. Lu, Y. Xie and Y. Liu, Controllable morphology evolution of electrodeposited $\mathrm{ZnO}$ nano-/micro-scale structures in aqueous solution, Mater. Des., 2009, 30, 1704-1711.

160 S. Cho, S.-H. Jung and K.-H. Lee, Morphology-Controlled Growth of $\mathrm{ZnO}$ Nanostructures Using Microwave Irradiation: from Basic to Complex Structures, J. Phys. Chem. C, 2008, 112, 12769-12776.

161 M. A. Bratescu, O. Takai and N. Saito, One-step synthesis of gold bimetallic nanoparticles with various metalcompositions, J. Alloys Compd., 2013, 562, 74-83.

162 H. Toyota, S. Nomura, Y. Takahashi and S. Mukasa, Submerged synthesis of diamond in liquid alcohol plasma, Diamond Relat. Mater., 2008, 17, 1902-1904.

163 G. Panomsuwan, N. Saito and T. Ishizaki, Electrocatalytic oxygen reduction on nitrogen-doped carbon nanoparticles derived from cyano-aromatic molecules via a solution plasma approach, Carbon, 2016, 98, 411-420.

164 T. Morishita, T. Ueno, G. Panomsuwan, J. Hieda, A. Yoshida, M. A. Bratescu and N. Saito, Fastest Formation Routes of Nanocarbons in Solution Plasma Processes, Sci. Rep., 2016, 6, 36880, DOI: 10.1038/ srep36880. 
165 A. Watthanaphanit, G. Panomsuwan and N. Saito, A novel one-step synthesis of gold nanoparticles in an alginate gel matrix by solution plasma sputtering, RSC Adv., 2014, 4, 1622-1629.

$166 \mathrm{X}$. L. Hu, O. Takai and N. Saito, Synthesis of gold nanoparticles by solution plasma sputtering in various solvents, J. Phys.: Conf. Ser., 2013, 417, 012030.

167 C. Tsukada, T. Mizutani, S. Ogawa, T. Nomoto, Y. Abe, H. Nameki, K. Matsuo, G. Kutluk and S. Yagi, Adsorption reaction of $L$-cysteine on $\mathrm{Au}$ nanoparticle prepared by solution plasma, e-J. Surf. Sci. Nanotechnol., 2013, 11, 18-24.

168 T. Mizutani, T. Murai, H. Nameki, T. Yoshida and S. Yagi, In situ ultraviolet-visible absorbance measurement during and after solution plasma sputtering for preparation of colloidal gold nanoparticles, Jpn. J. Appl. Phys., 2014, 53, 11RA03.

169 J.-K. Lung, J.-C. Huang, D.-C. Tien, C.-Y. Liao, K.-H. Tseng, T.-T. Tsung, W.-S. Kao, T.-H. Tsai, C.-S. Jwo, H.-M. Lin and L. Stobinskif, Preparation of gold nanoparticles by arc discharge in water, J. Alloys Compd., 2007, 434-435, 655658.

170 S. M. Kim, G. S. Kim and S. Y. Lee, Effects of PVP and KCl concentrations on the synthesis of gold nanoparticles using a solution plasma processing, Mater. Lett., 2008, 62, 4354-4356.

171 Y. K. Heo, M. A. Bratescu, T. Ueno and N. Saito, Synthesis of mono-dispersed nanofluids using solution plasma, J. Appl. Phys., 2014, 116, 024302.

172 S.-P. Cho, M. A. Bratescu, N. Saito and O. Takai, Microstructural characterization of gold nanoparticles synthesized by solution plasma processing, Nanotechnology, 2011, 22, 455701.

173 X. Hu, S.-P. Cho, O. Takai and N. Saito, Rapid synthesis and structural characterization of well-defined gold clusters by solution plasma sputtering, Cryst. Growth Des., 2012, 12, 119-123.

174 Y. K. Heo and S. Y. Lee, Effects of the gap distance on the characteristics of gold nanoparticles in nanofluids synthesized using solution plasma processing, Met. Mater. Int., 2011, 17, 431-434.

175 N. Saito, J. Hieda and O. Takai, Synthesis process of gold nanoparticles in solution plasma, Thin Solid Films, 2009, 518, 912-917.

176 O. Takai, Solution plasma processing (SPP), Pure Appl. Chem., 2008, 80, 2003-2011.

177 J. Hieda, N. Saito and O. Takai, Exotic shapes of gold nanoparticles synthesized using plasma in aqueous solution, J. Vac. Sci. Technol., A, 2008, 26, 854-856.

178 J. Hieda, N. Saito and O. Takai, Size-regulated gold nanoparticles fabricated by a discharge in reverse micelle solutions, Surf. Coat. Technol., 2008, 202, 5343-5346.

179 A. A. Ashkarran, A. Iraji zad, S. M. Mahdavi, M. M. Ahadian and M. R. Hormozi nezhad, Rapid and efficient synthesis of colloidal gold nanoparticles by arc discharge method, Appl. Phys. A, 2009, 96, 423-428.

180 A. A. Ashkarran, A. Zad, M. M. Ahadian and M. R. HormoziNezhad, Stability, size and optical properties of colloidal silver nanoparticles prepared by electrical arc discharge in water, Eur. Phys. J.: Appl. Phys., 2009, 48, 10601.

181 C.-H. Lo, T.-T. Tsung and H.-M. Lin, Preparation of silver nanofluid by the submerged arc nanoparticle synthesis system (SANSS), J. Alloys Compd., 2007, 434-435, 659-662.

182 D.-C. Tien, K.-H. Tseng, C.-Y. Liao and T.-T. Tsung, Identification and quantification of ionic silver from colloidal silver prepared by electric spark discharge system and its antimicrobial potency study, J. Alloys Compd., 2009, 473, 298-302.

183 C. Cho, Y. W. Choi, C. Kang and G. W. Lee, Effects of the medium on synthesis of nanopowders by wire explosion process, Appl. Phys. Lett., 2007, 91, 141501.

184 H. Lee, S. H. Park, S.-C. Jung, J.-J. Yun, S.-J. Kim and D.-H. Kim, Preparation of nonaggregated silver nanoparticles by the liquid phase plasma reduction method, J. Mater. Res., 2013, 28, 1105-1110.

185 A. A. Ashkarran, A novel method for synthesis of colloidal silver nanoparticles by arc discharge in liquid, Curr. Appl. Phys, 2010, 10, 1442-1447.

186 B. G. Rodriguez-Méndez, R. López-Callejas, M. T. Olguin, R. Valencia-Alvarado, A. Mercado-Cabrera, R. PeñaEguiluz and A. E. Muñoz-Castro, Growth of Ag particles from Ag-zeolite by pulsed discharges in water and their antibacterial activity, Microporous Mesoporous Mater., 2017, 244, 235-243.

$187 \mathrm{X} . \mathrm{Hu}, \mathrm{O}$. Takai and N. Saito, Simple synthesis of platinum nanoparticles by plasma sputtering in water, Jpn. J. Appl. Phys., 2013, 52, 01AN05.

188 S.-Y. Xie, Z.-J. Ma, C.-F. Wang, S.-C. Lin, Z.-Y. Jiang, R.-B. Huang and L.-S. Zheng, Preparation and selfassembly of copper nanoparticles via discharge of copper rod electrodes in a surfactant solution: a combination of physical and chemical processes, $J$. Solid State Chem., 2004, 177, 3743-3747.

189 P. Pootawang, N. Saito and S. Y. Lee, Discharge time dependence of a solution plasma process for colloidal copper nanoparticle synthesis and particle characteristics, Nanotechnology, 2013, 24, 055604.

190 V. S. Burakov, N. A. Savastenko, N. V. Tarasenko and E. A. Nevar, Synthesis of nanoparticles using a pulsed electrical discharge in a liquid, J. Appl. Spectrosc., 2008, 75, 114-124.

191 P. Pootawang, N. Saito, O. Takai and S.-Y. Lee, Synthesis and characteristics of $\mathrm{Ag} / \mathrm{Pt}$ bimetallic nanocomposites by arc discharge solution plasma processing, Nanotechnology, 2012, 23, 395602.

192 S. H. Sun and S.-C. Jung, Facile synthesis of bimetallic Ni$\mathrm{Cu}$ nanoparticles using liquid phase plasma method, Korean J. Chem. Eng., 2016, 33, 1075-1079.

193 D. G. Tong, W. Chu, P. Wu and L. Zhang, Honeycomblike Co-B amorphous alloy catalysts assembled by a solution plasma process show enhanced catalytic hydrolysis activity for hydrogen generation, $R S C A d v ., 2012,2$, 23692376.

194 N. Sano, H. Wang, M. Chhowalla, I. Alexandrou, G. A. J. Amaratunga, M. Naito and T. Kanki, Fabrication 
of inorganic molybdenum disulfide fullerenes by arc in water, Chem. Phys. Lett., 2003, 368, 331-337.

195 D. Delaportas, P. Svarnas, I. Alexandrou, A. Siokou, K. Black and $\mathrm{J}$. W. Bradley, $\gamma-\mathrm{Al}_{2} \mathrm{O}_{3}$ nanoparticle production by arcdischarge in water: in situ discharge characterization and nanoparticle investigation, J. Phys. D: Appl. Phys., 2009, 42, 245204.

196 M. Farajimotlagh, R. Poursalehi and M. Aliofkhazraei, Synthesis mechanisms, optical and structural properties of $\eta-\mathrm{Al}_{2} \mathrm{O}_{3}$ based nanoparticles prepared by DC arc discharge in environmentally friendly liquids, Ceram. Int., 2017, 43, 7717-7723.

197 A. A. Ashkarran, M. Kavianipour, S. M. Aghigh, S. A. A. Afshar, S. Saviz and A. I. Zad, On the formation of $\mathrm{TiO}_{2}$ nanoparticles via submerged arc discharge technique: synthesis, characterization and photocatalytic properties, J. Cluster Sci., 2010, 21, 753-766.

198 T. Jedsukontorn, T. Ueno, N. Saito and M. Hunsom, Facile preparation of defective black $\mathrm{TiO}_{2}$ through the solution plasma process: effect of parametric changes for plasma discharge on its structural and optical properties, J. Alloys Compd., 2017, 726, 567-577.

199 N. Su, X. Hu, J. Zhang, H. Huang, J. Cheng, J. Yu and C. Ge, Plasma-induced synthesis of $\mathrm{Pt}$ nanoparticles supported on $\mathrm{TiO}_{2}$ nanotubes for enhanced methanol electro-oxidation, Appl. Surf. Sci., 2017, 399, 403-410.

200 N. Janpetcha, N. Saitob and R. Rujiravanita, Fabrication of bacterial cellulose-ZnO composite via solution plasma process for antibacterial applications, Carbohydr. Polym., 2016, 148, 335-344.

201 T. Velusamy, A. Liguori, M. Macias-Montero, D. B. Padmanaban, D. Carolan, M. Gherardi, V. Colombo, P. Maguire, V. Svrcek and D. Mariotti, Ultra-small CuO nanoparticles with tailored energy-band diagram synthesized by a hybrid plasma-liquid process, Plasma Processes Polym., 2017, 14, e1600224.

202 J. Liu, B. He, Q. Chen, H. Liu, J. Li, Q. Xiong, X. Zhang, S. Yang, G. Yue and Q. H. Liu, Plasma electrochemical synthesis of cuprous oxide nanoparticles and their visible-light photocatalytic effect, Electrochim. Acta, 2016, 222, 1677-1681.

203 T. H. Kim, N. S. A. Eom, S.-O. Kang and Y.-H. Choa, Plasmaassisted electrolytic synthesis of $\operatorname{In}(\mathrm{OH})_{3}$ nanocubes for thermal transformation into $\operatorname{In}_{2} \mathrm{O}_{3}$ nanocubes with a controllable Sn content, RSC Adv., 2016, 6, 20337-20342.

204 M. T. Beck, Z. Dinya, S. Kéki and L. Papp, Formation of $\mathrm{C}_{60}$ and polycyclic aromatic hydrocarbons upon electric discharges in liquid toluene, Tetrahedron, 1993, 49, 285290.

205 V. Scuderi, C. Bongiorno, G. Faraci and S. Scalese, Effect of the liquid environment on the formation of carbon nanotubes and graphene layers by arcing processes, Carbon, 2012, 50, 2365-2369.

206 Y. L. Hsin, K. C. Hwang, F.-R. Chen and J.-J. Kai, Production and in-situ metal filling of carbon nanotubes in water, $A d v$. Mater., 2001, 13, 830-833.
207 N. Sano, M. Naito, M. Chhowalla, T. Kikuchi, S. Matsuda, K. Iimura, H. Wang, T. Kanki and G. A. J. Amaratunga, Pressure effects on nanotubes formation using the submerged arc in water method, Chem. Phys. Lett., 2003, 378, 29-34.

208 H. W. Zhu, X. S. Li, B. Jiang, C. L. Xu, Y. F. Zhu, D. H. Wu and $\mathrm{X}$. H. Chen, Formation of carbon nanotubes in water by the electric-arc technique, Chem. Phys. Lett., 2002, 366, 664-669.

209 M. V. Antisari, R. Marazzi and R. Krsmanovic, Synthesis of multiwall carbon nanotubes by electric arc discharge in liquid environments, Carbon, 2003, 41, 2393-2401.

210 N. Matsuda, T. Nakashima, T. Kato and H. Shiroishi, Synthesis of multiwall carbon nanotube-supported platinum catalysts by solution plasma processing for oxygen reduction in polymer electrolyte fuel cells, Electrochim. Acta, 2014, 146, 73-78.

211 A. Hamdan, H. Kabbara, M.-A. Courty, M. S. Cha, J.-M. Martinez and T. Belmonte, Synthesis of Carbon? Metal Multi-Strand Nanocomposites by Discharges in Heptane Between Two Metallic Electrodes, Plasma Chem, Plasma Processes Polym., 2017, 37, 1069-1090.

212 P. Pootawang and S. Y. Lee, Rapid synthesis of Ag nanoparticles-embedded mesoporous silica via solution plasma and its catalysis for 4-nitrophenol reduction, Mater. Lett., 2012, 80, 1-4.

213 P. Pootawang, N. Saito and O. Takai, Ag nanoparticle incorporation in mesoporous silica synthesized by solution plasma and their catalysis for oleic acid hydrogenation, Mater. Lett., 2011, 65, 1037-1040.

214 A. I. Ekimov and A. A. Onushchenko, Quantum size effect in three-dimensional microscopic semiconductor crystals, JETP Lett., 1981, 34, 345-349.

215 C. P. Collier, T. Vossmeyer and J. R. Heath, Nanocrystal superlattices, Annu. Rev. Phys. Chem., 1998, 49, 371-404.

216 A. D. Yoffe, Semiconductor quantum dots and related systems: Electronic, optical, luminescence and related properties of low dimensional systems, Adv. Phys., 2001, 50, 1-208.

217 Quantum dots: Fundamentals, applications, and frontiers, ed. B. A. Joyce, P. C. Kelires, A. G. Naumovets and D. Vvedensky, Springer, 2005.

218 Y. Wei, H. Yu, H. Li, H. Ming, K. Pan, H. Huang, Y. Liu and Z. Kang, Liquid-phase plasma synthesis of silicon quantum dots embedded in carbon matrix for lithium battery anodes, Mater. Res. Bull., 2013, 48, 4072-4077.

219 S. K. S. Gupta, Contact Glow Discharge Electrolysis: A Novel Tool for Manifold Applications, Plasma Chem. Plasma Process., 2017, 37, 897-945.

220 M. Akiyama, S. Kono, G. Imada, S. Ihara, T. Sugai, D. Wang and S. Katsuki, Use of plasma in liquid for fishing industry, J. Plasma Fusion Res., 2014, 90, 595-600.

$221 \mathrm{H}$. Akiyama, Streamer discharges in liquids and their applications, IEEE Trans. Dielectr. Electr. Insul., 2000, 7, 646-653. 
222 M. A. Malik, A. Ghaffar and S. A. Malik, Water purification by electrical discharges, Plasma Sources Sci. Technol., 2001, 10, 82-91.

223 Y. Matsui, N. Takeuchi, K. Sasaki, R. Hayashi and K. Yasuoka, Experimental and theoretical study of aceticacid decomposition by a pulsed dielectric-barrier plasma in a gas-liquid two-phase flow, Plasma Sources Sci. Technol., 2011, 20, 034015-034026.

224 H. F. Schroder and R. J. W. Meesters, Stability of fluorinated surfactants in advanced oxidation processes-A follow up of degradation products using flow injection-mass spectrometry, liquid chromatography-mass spectrometry and liquid chromatography-multiple stage mass spectrometry, J. Chromatogr. A, 2005, 1082, 110-119.

225 H. Hori, E. Hayakawa, H. Einaga, S. Kutsuna, K. Koike, T. Ibusuki, H. Kiatagawa and R. Arakawa, Decomposition of environmentally persistent perfluorooctanoic acid in water by photochemical approaches, Environ. Sci. Technol., 2004, 38, 6118-6124.

226 S. Horikoshi, A. Tsuchida, H. Sakaib, M. Abe and N. Serpone, Microwave discharge electrodeless lamps (MDELs). VI. Performance evaluation of a novel microwave discharge granulated electrodeless lamp (MDGEL)-photoassisted defluorination of perfluoroalkoxy acids in aqueous media, J. Photochem. Photobiol., A, 2011, 222, 97-104.

227 H. Hori, A. Yamamoto, E. Hayakawa, S. Taniyasu, N. Yamashita and S. Kutsuna, Efficient Decomposition of Environmentally Persistent Perfluorocarboxylic Acids by Use of Persulfate as a Photochemical Oxidant, Environ. Sci. Technol., 2005, 39, 2383-2388.

228 M. Shintani, Y. Naito, S. Yamada, Y. Nomura, S. Zhou, Y. Nakashimada and M. Hosomi, Degradation of Perfluorooctane- sulfonate (PFOS) and Perfluorooctanoic Acid (PFOA) by Mechanochemical Treatment, Kagaku Kogaku Ronbunshu, 2008, 34, 539-544.

229 H. Moriwaki, Y. Takagi, M. Tanaka, K. Tsuruho, K. Okitsu and Y. Maeda, Sonochemical Decomposition of Perfluorooctane Sulfonate and Perfluorooctanoic Acid, Environ. Sci. Technol., 2005, 39, 3388-3392.

230 T. Ohshima, K. Okuyama and M. Sato, Effect of culture temperature on high-voltage pulse sterilization of Escherichia coli, J. Electrost., 2002, 55, 227-235.

231 M. Sato, T. Ohgiyama and J. S. Clemens, Formation of chemical species and their effects on microorganisms using a pulsed high voltage discharge in water, IEEE Trans. Ind. Appl., 1996, 32, 106-112.

232 D. R. Grymonpré, W. C. Finney and B. R. Locke, Aqueousphase pulsed streamer corona reactor using suspended activated carbon particles for phenol oxidation: modeldata comparison, Chem. Eng. Sci., 1999, 54, 3095-3105.

233 Y. Zhang, J. Zheng, X. Qu and H. Chen, Effect of granular activated carbon on degradation of methyl orange when applied in combination with high voltage pulse discharge, J. Colloid Interface Sci., 2007, 316, 523-530.

234 X. L. Hao, X. W. Zhang and L. C. Lei, Degradation characteristics of toxic contaminant with modified activated carbons in aqueous pulsed discharge plasma process, Carbon, 2009, 47, 153-161.

235 G. Qu, D. Liang, D. Qu, Y. Huang, T. Liu, H. Mao, P. Ji and D. Huang, Simultaneous removal of cadmium ions and phenol from water solution by pulsed corona discharge plasma combined with activated carbon, Chem. Eng. J., 2013, 228, 28-35.

236 G. Z. Qu, N. Lu, J. Li, Y. Wu, G. F. Li and D. Li, Simultaneous pentachlorophenol decomposition and granular activated carbon regeneration assisted by dielectric barrier discharge plasma, J. Hazard. Mater., 2009, 172, 472-478.

237 M. Sahni and B. R. Locke, Degradation of chemical warfare agent simulants using gas-liquid pulsed streamer discharges, J. Hazard. Mater., 2006, 137, 1025-1034.

238 P. M. K. Reddy and C. Subrahmanyam, Green approach for wastewater treatmentdegradation and mineralization of aqueous organic pollutants by discharge plasma, Ind. Eng. Chem. Res., 2012, 51, 11097-11103.

239 B. P. Dojčinović, G. M. Roglić, B. M. Obradović, M. M. Kuraica, M. M. Kostić, J. Nešić and D. D. Manojlović, Decolorization of reactive textile dyes using water falling film dielectric barrier discharge, $J$. Hazard. Mater., 2011, 192, 763-771.

240 C. M. Du, J. H. Yan and B. G. Cheron, Degradation of 4chlorophenol using a gas-liquid gliding arc discharge plasma reactor, Plasma Chem. Plasma Process., 2007, 27, 635-646.

241 J. Gao, J. Yu, Q. Lu, X. He, W. Yang, Y. Li, L. Pu and Z. Yang, Decoloration of alizarin red $\mathrm{S}$ in aqueous solution by glow discharge electrolysis, Dyes Pigm., 2008, 76, 47-52.

242 Y. J. Liu and X. Z. Jiang, Phenol degradation by a nonpulsed diaphragm glow discharge in an aqueous solution, Environ. Sci. Technol., 2005, 39, 8512-8517.

243 Y. Shen, L. Lei, X. Zhang, M. Zhou and Y. Zhang, Effect of various gases and chemical catalysts on phenol degradation pathways by pulsed electrical discharges, $J$. Hazard. Mater., 2008, 150, 713-722.

244 M. R. Ghezzar, F. Abdelmalek, M. Belhadj, N. Benderdouche and A. Addou, Enhancement of the bleaching and degradation of textile wastewaters by Gliding arc discharge plasma in the presence of $\mathrm{TiO}_{2}$ catalyst, J. Hazard. Mater., 2009, 164, 1266-1274.

245 K. Marouf-Khelifa, F. Abdelmalek, A. Khelifa and A. Addou, $\mathrm{TiO}_{2}$-assisted degradation of a perfluorinated surfactant in aqueous solutions treated by gliding arc discharge, Chemosphere, 2008, 70, 1995-2001.

246 M. R. Ghezzar, S. Ognier, S. Cavadias, F. Abdelmalek and A. Addou, DBD plate- $\mathrm{TiO}_{2}$ treatment of Yellow Tartrazine azo dye solution in falling film, Sep. Purif. Technol., 2013, 104, 250-255.

247 X. L. Hao, M. H. Zhou and L. C. Lei, Non-thermal plasmainduced photocatalytic degradation of 4-chlorophenol in water, J. Hazard. Mater., 2007, 141, 475-482.

248 H. Wang, J. Chu, H. Ou, R. Zhao and J. Han, Analysis of $\mathrm{TiO}_{2}$ photocatalysis in a pulsed discharge system for phenol degradation, J. Electrost., 2009, 67, 886-889. 
249 A. G. Bubnov, E. Y. Burova, V. I. Grinevich, V. V. Rybkin, J. K. Kim and H. S. Choi, Comparative actions of $\mathrm{NiO}$ and $\mathrm{TiO}_{2}$ catalysts on the destruction of phenol and its derivatives in a dielectric barrier discharge, Plasma Chem. Plasma Process., 2007, 27, 177-187.

250 T. Sakugawa, N. Aoki, H. Akiyama, K. Ishibashi, M. Watanabe, A. Kouda and K. Suematsu, A method of cyanobacteria treatment using underwater pulsed streamer-like discharge, IEEE Trans. Plasma Sci., 2014, 42, 794-798.

251 See e.g., http://www.kumamoto-u.ac.jp/daigakujouhou/ kouhou/pressrelease/2013_file/release 130819.pdf, accessed August 2017.
252 See e.g., http://mitsubishielectric.co.jp/corporate/randd/ spotlight/a25/index.html, accessed August 2017.

253 T. A. Kareem and A. A. Kaliani, Glow discharge plasma electrolysis for nanoparticles synthesis, Ionics, 2012, 18, 315-327.

254 Q. Chen, J. Li and Y. Li, A review of plasma-liquid interactions for nanomaterial synthesis, J. Phys. D: Appl. Phys., 2015, 48, 424005.

255 P. Rumbach and D. B. Go, Perspectives on Plasmas in Contact with Liquids for Chemical Processing and Materials Synthesis, Top. Catal., 2017, 60, 799-811. 